\title{
Platinum-group elements (PGE) and rhenium in marine sediments across the Cretaceous- Tertiary boundary: Constraints on Re-PGE transport in the marine environment
}

\author{
Cin-Ty Aeolus Lee, ${ }^{1} *$ Gerald J. Wasserburg, ${ }^{\prime}$ and Frank T. Kyte ${ }^{2}$ \\ ${ }^{1}$ Lunatic Asylum, Division of Geological and Planetary Sciences, MC 170-25, Caltech, 1200 East California Boulevard, Pasadena, \\ CA 91125 , USA \\ ${ }^{2}$ Institute of Geophysics and Planetary Physics, University of California, Los Angeles, CA 90095-1567, USA
}

(Received April 22, 2002; accepted in revised form August 7, 2002)

\begin{abstract}
The nature of Re-platinum-group element (PGE; Pt, Pd, Ir, Os, Ru) transport in the marine environment was investigated by means of marine sediments at and across the Cretaceous-Tertiary boundary (KTB) at two hemipelagic sites in Europe and two pelagic sites in the North and South Pacific. A traverse across the KTB in the South Pacific pelagic clay core found elevated levels of Re, Pt, Ir, Os, and Ru, each of which is approximately symmetrically distributed over a distance of $\sim 1.8 \mathrm{~m}$ across the KTB. The Re-PGE abundance patterns are fractionated from chondritic relative abundances: $\mathrm{Ru}, \mathrm{Pt}, \mathrm{Pd}$, and $\mathrm{Re}$ contents are slightly subchondritic relative to Ir, and Os is depleted by $\sim 95 \%$ relative to chondritic Ir proportions. A similar depletion in Os ( $\sim 90 \%)$ was found in a sample of the pelagic KTB in the North Pacific, but it is enriched in $\mathrm{Ru}, \mathrm{Pt}, \mathrm{Pd}$, and Re relative to Ir. The two hemipelagic KTB clays have near-chondritic abundance patterns. The 1.8-m-wide Re-PGE peak in the pelagic South Pacific section cannot be reconciled with the fallout of a single impactor, indicating that postdepositional redistribution has occurred. The elemental profiles appear to fit diffusion profiles, although bioturbation could have also played a role. If diffusion had occurred over $\sim 65 \mathrm{Ma}$, the effective diffusivities are $\sim 10^{-13} \mathrm{~cm}^{2} / \mathrm{s}$, much smaller than that of soluble cations in pore waters $\left(\sim 10^{-6} \mathrm{~cm}^{2} / \mathrm{s}\right)$. The coupling of $\mathrm{Re}$ and the PGEs during redistribution indicates that postdepositional processes did not significantly fractionate their relative abundances. If redistribution was caused by diffusion, then the effective diffusivities are the same. Fractionation of Os from Ir during the KTB interval must therefore have occurred during aqueous transport in the marine environment. Distinctly subchondritic Os/Ir ratios throughout the Cenozoic in the South Pacific core further suggest that fractionation of Os from Ir in the marine environment is a general process throughout geologic time because most of the inputs of Os and Ir into the ocean have $\mathrm{Os} / \mathrm{Ir}$ ratios $\geq 1$. Mass balance calculations show that $O$ s and $\mathrm{Re}$ burial fluxes in pelagic sediments account for only a small fraction of the riverine $\mathrm{Os}(<10 \%)$ and $\operatorname{Re}(<0.1 \%)$ inputs into the oceans. In contrast, burial of Ir in pelagic sediments is similar to the riverine Ir input, indicating that pelagic sediments are a much larger repository for Ir than for Os and Re. If all of the missing Os and Re is assumed to reside in anoxic sediments in oceanic margins, the calculated burial fluxes in anoxic sediments are similar to observed burial fluxes. However, putting all of the missing Os and Re into estuarine sediments would require high concentrations to balance the riverine input and would also fail to explain the depletion of Os at pelagic KTB sites, where at most $\sim 25 \%$ of the K-T impactor's Os could have passed through estuaries. If Os is preferentially sequestered in anoxic marine environments, it follows that the Os/Ir ratio of pelagic sediments should be sensitive to changes in the rates of anoxic sediment deposition. There is thus a clear fractionation of Os and Re from Ir in precipitation out of sea water in pelagic sections. Accordingly, it is inferred here that $\mathrm{Re}$ and Os are removed from sea water in anoxic marine depositional regimes. Copyright $(2003$ Elsevier Science Ltd
\end{abstract}

\section{INTRODUCTION}

The platinum-group elements (PGE) are $\mathrm{Pt}, \mathrm{Pd}, \mathrm{Ir}, \mathrm{Os}, \mathrm{Rh}$, and $\mathrm{Ru}$. Along with $\mathrm{Re}$, these elements are gaining importance in studies of weathering, diagenesis, and paleoclimate. For example, the Re-Os radiogenic decay system has been used to track secular changes in the relative proportions of continental, hydrothermal, and extraterrestrial input of Os into the oceans (e.g., Peucker-Ehrenbrink, 1996; Peucker-Ehrenbrink and Ravizza, 2000). In addition, the variable speciations of $R e$ and the PGEs make them potentially useful indicators of ocean oxidation states (Anbar et al., 1996; Crusius et al., 1996; Morford and Emerson, 1999). However, interpreting Os isoto-

* Author to whom correspondence should be addressed, at Department of Earth Science, MS-126, Rice University, P.O. Box 1892, Houston TX 77251-1892, USA (ctlee@ rice.edu). pic ratios and PGE elemental abundance data is complicated by an incomplete understanding of the behaviors of Re-PGE-Au during weathering, diagenesis, and transport in the marine environment. Furthermore, the full sources of Os (including cosmic dust infall and mantle additions from spreading centers) and the sinks for Os are not readily quantifiable (e.g., Sharma and Wasserburg, 1997; Sharma et al., 1999, 2000).

Sediments from the Cretaceous-Tertiary boundary (KTB) illustrate this point. The KTB coincides with a large Ir anomaly, which is now widely agreed to represent the fallout of a large meteorite impact. This leads to a simple prediction that the Ir anomaly should be manifested as a spike in the stratigraphic record corresponding to the time of impact and that the PGE abundance pattern of the spike should match that of the impactor, which, on the basis of the uniform relative abundances of PGEs in meteorites (Larimer and Wasson, 1988) and 


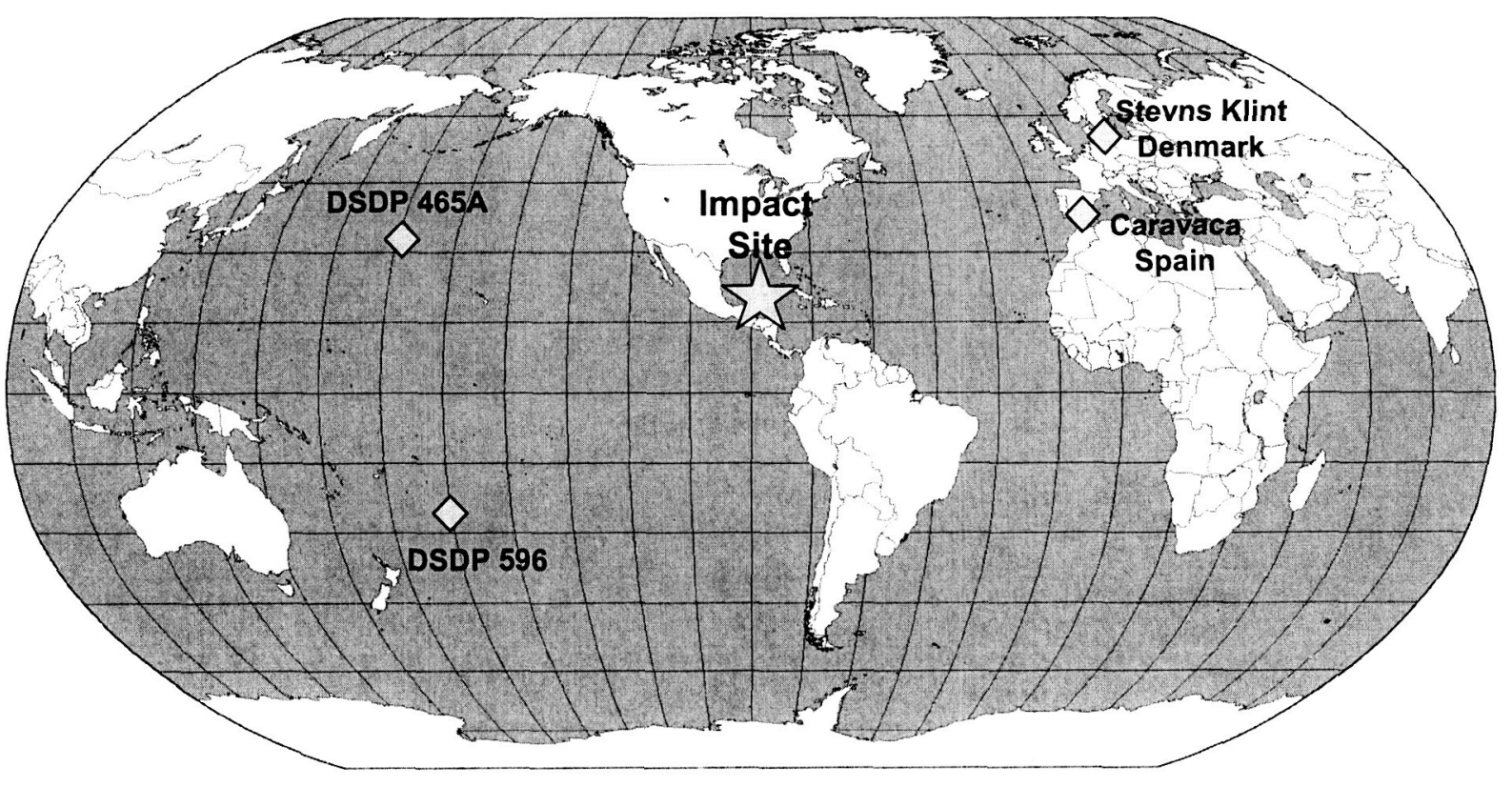

Fig. 1. Locations of the sites analyzed in this study. Star represents K-T impact site.

the $\mathrm{Cr}$ isotopic composition of the KTB sediments (Shukolyukov and Lugmair, 1998), was probably chondritic. However, a number of studies have shown that the Ir anomaly is often spread out over substantial distances in the sedimentary section that includes the KTB (Kastner, 1984; Kyte et al., 1985, 1993, 1996; Robin et al., 1991; Zhou et al., 1991). In some cases, this distribution corresponds to several million years of deposition (Zhou et al., 1991), which is too long to be reconciled with a single impact event. There are very few KTB studies that consider most of the PGEs. The available data show that PGE abundance patterns at various KTB sites can depart significantly from chondritic values (e.g., Kyte et al., 1985). This suggests that the PGE fallout was fractionated from its initially chondritic proportions and redistributed before, during, or after deposition, or some combination of these. The goal of the present study is to use the distribution of Re-PGEs around the KTB to study the processes that fractionate and transport Re and the PGEs in the marine environment. The results of the KTB study will be combined with an investigation of Re-PGE content in pelagic sediments away from the KTB to draw more general inferences about the mechanisms of Re and PGE transport in the marine environment.

\section{SAMPLES}

\subsection{Pelagic Sites}

We examined the distribution of the PGEs ( $\mathrm{Pt}, \mathrm{Pd}$, Ir, Ru, Os) and $\mathrm{Re}$ at selected stratigraphic sections from KTB sites (Fig. 1). We analyzed a pelagic sediment core from the South Pacific (DSDP 596) at closely spaced intervals, including the KTB, which was previously identified at $20.10 \mathrm{~m}$ below the sediment-seawater interface (mbsf) on the basis of the highest Ir concentration peak (Zhou et al., 1991). The Ir anomaly in this core was found to span $\sim 1.8 \mathrm{~m}$. The upper $40 \mathrm{~m}$ of cores at Site 596 were recovered by hydraulic piston coring, which is con- sidered to have incurred minimal core disturbance. The core is characterized by metalliferous clays with very slow sediment accumulation rates $(\sim 0.3 \mathrm{~m} / \mathrm{Ma})$. All DSDP 596 sediments were dried in an oven at $60^{\circ} \mathrm{C}$ and then gently disaggregated and powdered by hand with a hammer covered with paper so that the samples always remained in a metal-free environment. The bulk sample was used for analyses.

We also analyzed the KTB clay from a pelagic North Pacific site (DSDP 465A) dominated by calcareous oozes. The KTB was recognized by the shipboard scientific party (Thiede et al., 1992) on the basis of its foraminiferal biostratigraphy (Boersma, 1981), and it is located in sections 3 and 4 of core 3 in Hole 465A ( $\sim 62.4 \mathrm{mbsf}$ ). Unfortunately, the Ir anomaly is smeared out over more than $0.4 \mathrm{~m}$ as a result of disturbance by rotary drilling (Kastner, 1984; Kyte et al., 1996). However, throughout this disturbed zone are fragments of a thin $(\sim 3$ $\mathrm{mm}$ ), black pyrite-rich layer, and one fragment was obtained from 3-3 123-124. On the basis of detailed paleontological analyses of an intact fragment of the KTB, Kyte et al. (1996) showed that the black layer corresponds to the actual biostratigraphic KTB. We obtained a sample, which contained the black layer. This boundary clay was carefully separated from the surrounding calcareous oozes and gently disaggregated. At the time of sampling, this core was nearly dry, so 465A samples were not oven heated.

\subsection{Hemipelagic Sites}

Two European hemipelagic KTB clays, now exposed on land (Caravaca, Spain, and Stevns Klint, Denmark), were examined. The location of the KTB and Ir peak at both of these sites has been previously identified (Alvarez et al., 1980; Smit and Hertogen, 1980). The Caravaca site is dominated by calcareous marls (Kyte et al., 1985). The base of the boundary clay is composed of a thin sanidine spherule-rich layer, in which the 

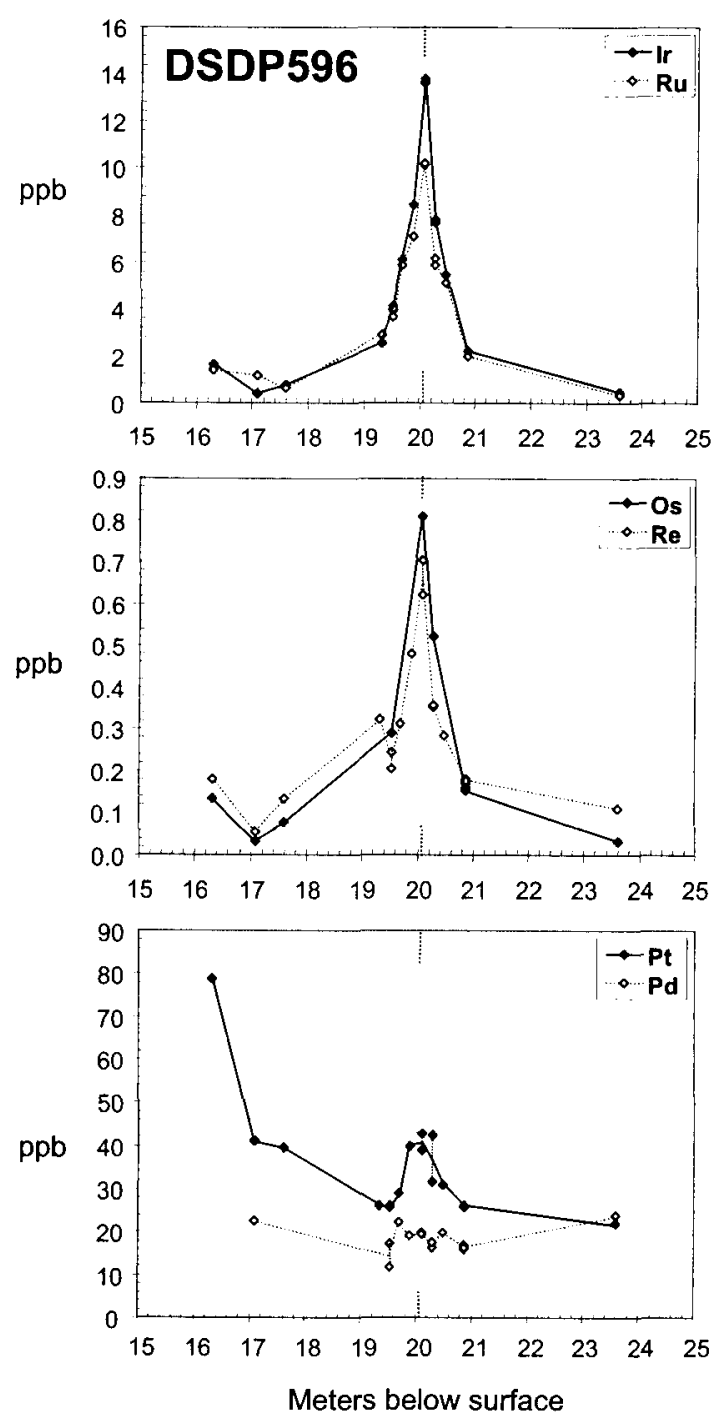

Fig. 2. Dry weight concentrations (ppb) of Re-PGEs vs. depth (meters below sediment-water interface) in DSDP 596, a pelagic clay section in the South Pacific. Duplicate analyses are shown. Gray vertical line shows the location of the KTB.

PGE anomaly is located (Smit and Hertogen, 1980). Kyte et al. (1985) carefully separated fragments of this boundary clay (SM503) from the surrounding marls and analyzed them for Re, $\mathrm{Ir}, \mathrm{Pt}, \mathrm{Pd}$, and $\mathrm{Os}$ by radiochemical neutron activation analysis. In this study, we also analyzed only the sanidine spherule-rich boundary clay. We did not analyze the same aliquot of sample from Kyte et al. (1985), but we attempted to repeat the same sampling procedure. The separated boundary clays were combined (yielding a total of $\sim 0.5 \mathrm{~g}$ ) and then gently disaggregated and homogenized by hand. The boundary clays were already dry, so they were not heated.

At Stevns Klint, we analyzed a thin $1-\mathrm{cm}$ layer located at the base of the "fish clay" that marks the KTB (Kastner, 1984; Kyte et al., 1985). The aliquot we analyzed is from the same bulk sample (SK10) analyzed by Kyte et al. (1985), but we also crushed, powdered, and homogenized our sample in a ceramic
Spex mill $(\sim 30 \mathrm{~g})$. SK10 was not heated because it was already dry.

\section{METHODS}

Although several PGE studies have been conducted on the above KTB sites, we sought to improve on these studies by analyzing Pt, Pd, $\mathrm{Ir}, \mathrm{Ru}, \mathrm{Os}$, and $\mathrm{Re}$ on the same aliquot of each sample and by conducting a PGE traverse across the KTB in DSDP 596. Sample powders were loaded in chilled, thick-walled borosilicate glass vessels (Carius Tubes; Shirey and Walker, 1995) along with a mixed Re-PGE tracer solution $\left({ }^{191} \mathrm{Ir},{ }^{198} \mathrm{Pt},{ }^{105} \mathrm{Pd},{ }^{99} \mathrm{Ru},{ }^{190} \mathrm{Os},{ }^{185} \mathrm{Re}\right)$ and $3 \mathrm{~mL}$ of aqua regia (glass vessels were cleaned in boiling aqua regia). Because of the limited amounts of sample available. less than $200 \mathrm{mg}$ were used for most of the dissolutions (although for samples away from the KTB, larger amounts were dissolved, up to $0.7 \mathrm{~g}$ ). The glass vessel was then sealed and heated to $230^{\circ} \mathrm{C}$ for $-72 \mathrm{~h}$. After opening the vessel, Os was extracted by a three-stage chloroform solvent extraction procedure and then stabilized in concentrated $\mathrm{HBr}$ overnight (during the initial stages of this study, Os was not extracted and hence was lost by volatilization). The $\mathrm{HBr}$ solution was then evaporated to near dryness and taken up in $0.15 \mathrm{~N} \mathrm{HCl}$ for analysis of $\mathrm{Os}$ by inductively coupled plasma mass spectrometry (ICP-MS). The residual aqua regia, containing $\mathrm{Pt}$, $\mathrm{Pd}, \mathrm{Ir}, \mathrm{Ru}$, and $\mathrm{Re}$, was then dried down and taken up in $\sim 0.5 \mathrm{~mL}$ of $0.07 \mathrm{~N} \mathrm{HCl}$ and passed through $0.5 \mathrm{~mL}$ of cation exchange resin (Bio-Rad AG50X-8 100 to 200 mesh cleaned with $6.7 \mathrm{~N} \mathrm{HCl}$ ) followed by elution with $1 \mathrm{~mL}$ of $0.07 \mathrm{~N} \mathrm{HCl}$; the majority of interfering cations were adsorbed onto the resin while Re and the PGEs passed through the column and were collected. Approximately half the elutant was then used directly for ICP-MS analysis of Re, Ir, Ru, and Pt. The other half of the elutant from the cation exchange column was then passed through anion exchange chemistry (BioRad AGIX-8 100 to 200 mesh) to further separate $\mathrm{Zr}$ and $\mathrm{Cd}$ from $\mathrm{Pd}$. A combination of $0.07 \mathrm{~N} \mathrm{HCl}$ and $0.8 \mathrm{~N} \mathrm{HNO}_{3}$ washes were used to elute $\mathrm{Zr}$ and $\mathrm{Cd}$ from the column. Concentrated $\mathrm{HCl}$ and $\mathrm{HNO}_{3}$ were then used to elute the $\mathrm{Re}, \mathrm{Ir}, \mathrm{Ru}, \mathrm{Pt}$, and $\mathrm{Pd}$, which were collected and taken up in $0.8 \mathrm{~N} \mathrm{HNO}_{3}$ for ICP-MS analysis. Analyses were performed by a magnetic-sector single-collector ICP-MS (ThermoFinnigan Element). Procedural blanks are $3 \pm 2$ pg for Os, $1 \pm 2 \mathrm{pg}$ of Ru, $24 \pm 8 \mathrm{pg}$ for Ir, $330 \pm 132 \mathrm{pg}$ for Pt, and $6 \pm 4 \mathrm{pg}$ for $\mathrm{Pd}(2 \sigma ; \mathrm{n}=3)$. The high Pt blank is likely derived from the glass vessel, but because of the high Pt concentrations in the samples, these blank levels are negligible. Over the period of this study, reproducibility on a $0.5 \mathrm{ppb}$ mixed PGE standard of normal isotopic composition was better than $3 \%(2 \sigma)$ for the isotope ratios used for isotope dilution calculations $\left({ }^{101} \mathrm{Ru} /{ }^{\prime \prime 9} \mathrm{Ru},{ }^{102} \mathrm{Ru} /{ }^{99} \mathrm{Ru},{ }^{106} \mathrm{Pd} /{ }^{105} \mathrm{Pd}\right.$, ${ }^{108} \mathrm{Pd} /{ }^{105} \mathrm{Pd},{ }^{187} \mathrm{Re} /{ }^{185} \mathrm{Re},{ }^{189} \mathrm{Os} /{ }^{190} \mathrm{Os},{ }^{192} \mathrm{Os} /{ }^{190} \mathrm{Os},{ }^{193} \mathrm{Ir} /{ }^{191} \mathrm{Ir},{ }^{194} \mathrm{Pt} /$ ${ }^{198} \mathrm{Pt},{ }^{195} \mathrm{Pt} /{ }^{198} \mathrm{Pt},{ }^{196} \mathrm{Pt} /{ }^{198} \mathrm{Pt}$ ). Mass fractionation factors were determined by running standards of normal isotopic composition (approximately every $30 \mathrm{~min}$ ) and then applying this correction factor to the sample measurements. Signal intensities were corrected for interferences from $\mathrm{Hg}$ on ${ }^{198} \mathrm{Pt}(<1 \%), \mathrm{Cd}$ on ${ }^{108} \mathrm{Pd}$ and ${ }^{106} \mathrm{Pd}(<10 \%)$, and $\mathrm{ZrO}$ on ${ }^{108} \mathrm{Pd}$ and ${ }^{106} \mathrm{Pd}(<1 \%)$. In some analyses, the $\mathrm{Cd}$ and/or $\mathrm{Zr}$ interference on $\mathrm{Pd}$ isotopes was too high $(>10 \%)$; such analyses are not reported. NiAr interferences on Ru were negligible, as was Pt on ${ }^{192} \mathrm{Os}$. Spikes were calibrated against single-element Alfa-Aesar/JohnsonMatthey Specpure PGE standard solutions and a gravimetric Os standard made from high purity Os salts (Lee et al., 2001; Yin et al., 2001). Reproducibility on different aliquots of the same sample are shown in Table 1.

In a previous study of the PGE content of ultramafic rocks (Lee, 2002), we found that the data obtained by the fire assay method agreed with our determinations by acid digestions in sealed glass vessels. However, for reasons we do not understand, we found that the fire assay method, when applied to DSDP 596 samples, gave poor samplespike equilibration, resulting in some instances to a two- to threefold underestimate of the PGE concentrations compared with acid digestion in sealed glass vessels. 

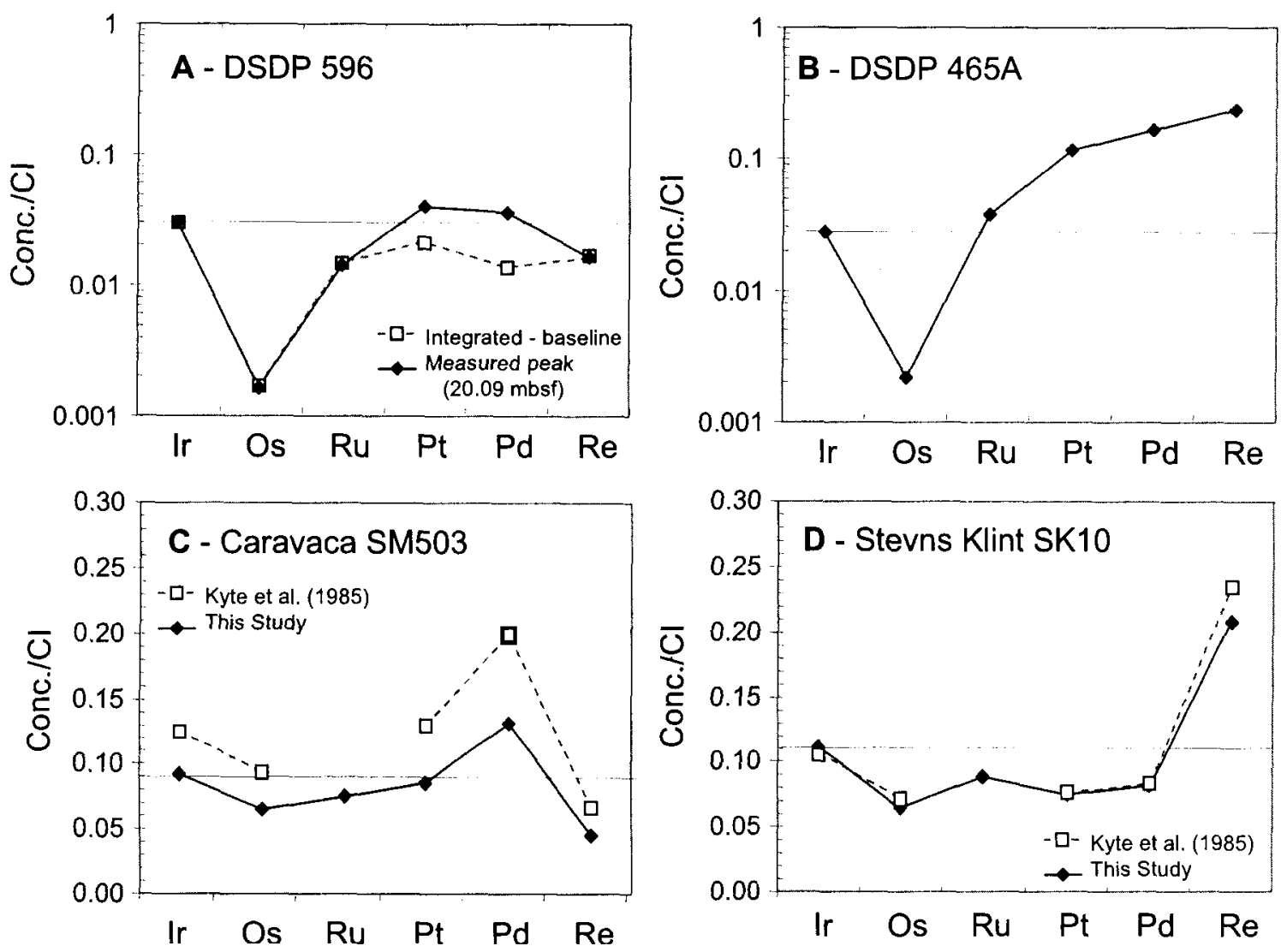

Fig. 3. Chondrite-normalized (CI) Re-PGE abundance patterns at the peak (20.09 mbsf) for each KTB site. (A) Abundances at the peak of the Re-PGE profile at the pelagic DSDP 596 (solid lines and solid diamonds). The integrated concentrations minus the baseline concentrations (normalized to $\mathrm{CI}$ and the measured peak at 20.09 mbsf) are denoted by the dotted lines and square symbols. (B) Elemental abundances of the KTB clay in the pelagic DSDP 465A core. (C) basal hemipelagic KTB clay from Caravaca, Spain (SM503). (D) hemipelagic KTB clay at Stevns Klint, Denmark (SK 10). Values for chondrite normalization are $\mathrm{Ru}=712, \mathrm{Pd}=560, \mathrm{Re}=36.5, \mathrm{Os}=486, \mathrm{Ir}=481, \mathrm{Pt}=990 \mathrm{ppb}$ (Anders and Grevesse, 1989). Horizontal dashed lines are drawn through Ir in each panel to aid visualization.

\section{RESULTS}

\subsection{Pelagic Sites}

\subsubsection{DSDP 596}

Dry weight concentrations for DSDP 596 are shown in Table 1 located at 20.09 mbsf (Fig. 2). Re, Pt, Ir, Os, and Ru are elevated at the KTB (Fig. 2), with the highest levels of these elements occurring in sample 3-4 49-50, located at 20.09 mbsf. Like Zhou et al. (1991), we assign the KTB to the position of the highest Ir concentrations. Pt, Ir, Os, and Ru levels decrease monotonically both up and down section from the peak, producing roughly symmetric concentration profiles over a width of $\sim 1.8 \mathrm{~m}$ for $\mathrm{Pt}$, Ir, Os and $\mathrm{Ru}$. With the exception of one anomalous sample $(0.77 \mathrm{~m}$ above the peak), Re is also characterized by a roughly symmetric profile spanning $\sim 1.8 \mathrm{~m}$. Most of our Ir measurements are in agreement to within $20 \%$ of the instrumental neutron activation analyses of Zhou and Kyte (1992). The Re, Ir, Ru, and Os contents at the KTB (20.09 mbsf) are approximately $10,30,15$, and 20 times higher, respectively, than the baseline (pre and post KTB sediments). Pt exhibits a slightly subdued peak, which is only a factor of two times higher than that of the pre-KTB sediments. There is a high baseline of $\mathrm{Pt}$ content ( $\sim 25 \mathrm{ppb}$ ) above and below the $\mathrm{KTB}$, and it rises to very high levels $\sim 2.5 \mathrm{~m}$ above the KTB. Pd differs from $\mathrm{Re}$ and the other PGEs in not displaying a well-defined peak at the KTB. Like Pt, the background Pd concentrations appear to be high (15 to $25 \mathrm{ppb}$ ) throughout the section. The rise in $\mathrm{Pd} \sim 3 \mathrm{~m}$ above the $\mathrm{KTB}$ is coincident with the rise in $\mathrm{Pt}$ and small rises in $\mathrm{Re}, \mathrm{Ir}, \mathrm{Os}$, and $\mathrm{Ru}$. However, the elevated Pd contents $\sim 3.5 \mathrm{~m}$ below the KTB are not accompanied by a rise in $\mathrm{Re}$ or any of the other PGEs.

Figure $3 \mathrm{~A}$ shows the chondrite-normalized concentrations (Anders and Grevesse, 1989) for the measured peak values ( $20.09 \mathrm{mbsf}$ ) and for the values obtained by integrating the concentrations over $\pm 0.9 \mathrm{~m}$ around the peak after subtracting out the baseline concentration. For Pt and Pd, there is a significant baseline ( $25 \mathrm{ppb}$ for $\mathrm{Pt}$ and $15 \mathrm{ppb}$ for $\mathrm{Pd}$ ) that must be subtracted to obtain their contents at the peak. Ir, Pt and Pd have roughly chondritic proportions at $20.09 \mathrm{mbsf}(\mathrm{Pt} / \mathrm{Ir}=1.4$ $\times(\mathrm{Pt} / \mathrm{Ir})_{\mathrm{CI}} ; \mathrm{Pd} / \mathrm{Ir}=0.9 \times(\mathrm{Pd} / \mathrm{Ir})_{\mathrm{Cl}}$, whereas $\mathrm{Ru}$, Re and $\mathrm{Os}$ appear to be significantly depleted relative to $\operatorname{Ir}(\mathrm{Ru} / \mathrm{Ir}=0.5 \times$ $\left.(\mathrm{Ru} / \mathrm{Ir})_{\mathrm{CI}} ; \mathrm{Re} / \mathrm{Ir}=0.6 \times(\mathrm{Re} / \mathrm{Ir})_{\mathrm{Cl}} ; \mathrm{Os} / \mathrm{Ir}=0.06 \times(\mathrm{Os} / \mathrm{Ir})_{\mathrm{Cl}}\right)$. Subchondritic $\mathrm{Ru} / \mathrm{Ir}, \mathrm{Re} / \mathrm{Ir}$, and $\mathrm{Os} / \mathrm{Ir}$ ratios at the peak (20.09 mbsf) are also obtained when the data are integrated over the 
Table 1. Dry weight concentrations.

\begin{tabular}{|c|c|c|c|c|c|c|c|c|c|}
\hline Site & mbsf & $\begin{array}{c}\mathrm{Ir} \\
(\mathrm{ppb})\end{array}$ & $\begin{array}{c}\text { Os } \\
(\mathrm{ppb})\end{array}$ & $\begin{array}{c}\mathrm{Ru} \\
(\mathrm{ppb})\end{array}$ & $\begin{array}{c}\mathrm{Pt} \\
(\mathrm{ppb})\end{array}$ & $\begin{array}{c}\mathrm{Pd} \\
(\mathrm{ppb})\end{array}$ & $\begin{array}{c}\mathrm{Re} \\
(\mathrm{ppb})\end{array}$ & $\mathrm{Os} / \mathrm{Ir}$ & $\mathrm{Pt} / \mathrm{Ir}$ \\
\hline \multicolumn{10}{|c|}{ Pelagic } \\
\hline \multicolumn{10}{|l|}{ South Pacific - DSDP 596} \\
\hline DSDP $596,1-1$ 143-145 CT1 & 1.43 & 0.324 & 0.107 & & 9.45 & & 0.156 & 0.331 & 29.2 \\
\hline DSDP 596, 1-2 52-54 CT1 & 2.02 & 0.269 & 0.115 & & 9.63 & & 0.232 & 0.426 & 35.8 \\
\hline DSDP $596,2-524-25$ CT1 & 11.74 & 1.48 & 0.147 & 1.62 & 48.4 & 4.16 & 0.112 & 0.099 & 32.7 \\
\hline DSDP 596, 3-1 121-122 CT1 & 16.31 & 1.61 & 0.134 & 1.37 & 78.7 & & 0.181 & 0.083 & 48.9 \\
\hline DSDP 596, 3-2 49-50 CT1 & 17.09 & 0.427 & 0.032 & 1.19 & 41.2 & 22.7 & 0.057 & 0.075 & 96.6 \\
\hline DSDP $596,3-2$ 100-102 CT1 & 17.6 & 0.769 & 0.077 & 0.630 & 39.7 & & 0.135 & 0.100 & 51.6 \\
\hline DSDP 596, 3-3 122-124 CT1 & 19.32 & 2.57 & & 2.91 & 26.1 & & 0.325 & & 10.1 \\
\hline DSDP 596, 3-3 143-144 CT1 & 19.53 & 3.93 & & 4.01 & 26.0 & 17.2 & 0.247 & & 6.62 \\
\hline DSDP 596, 3-3 143-144 CT2 & 19.53 & 4.11 & 0.291 & 3.64 & 25.7 & 11.7 & 0.206 & 0.071 & 6.25 \\
\hline DSDP 596, 3-4 10-11 CT1 & 19.7 & 6.13 & & 5.86 & 29.1 & 22.3 & 0.313 & & 4.75 \\
\hline DSDP 596, 3-4 29-30 CT1 & 19.89 & 8.46 & & 7.09 & 39.9 & 19.1 & 0.480 & & 4.71 \\
\hline DSDP 596, 3-4 49-50 CT2 & 20.09 & 13.6 & 0.809 & 10.1 & 42.8 & 19.7 & 0.704 & 0.059 & 3.15 \\
\hline DSDP 596, 3-4 49-50 CT3 & 20.09 & 13.8 & & 10.2 & 38.9 & 19.4 & 0.623 & & 2.82 \\
\hline DSDP 596, 3-4 68-69 CT1 & 20.28 & 7.81 & & 6.15 & 42.3 & 16.2 & 0.354 & & 5.42 \\
\hline DSDP 596, 3-4 68-69 CT2 & 20.28 & 7.68 & 0.523 & 5.85 & 31.7 & 17.4 & 0.357 & 0.068 & 4.12 \\
\hline DSDP 596, 3-4 88-89 CT1 & 20.48 & 5.45 & & 5.12 & 31.0 & 19.7 & 0.286 & & 5.69 \\
\hline DSDP $596,3-4$ 127-128 CT1 & 20.87 & 2.22 & 0.169 & & 26.0 & 16.8 & 0.181 & 0.076 & 11.7 \\
\hline DSDP 596, 3-4 127-128 CT2 & 20.87 & 2.20 & 0.154 & 1.96 & 25.9 & 15.8 & 0.176 & 0.070 & 11.8 \\
\hline DSDP 596, 3-6 100-102 CT1 & 23.6 & 0.489 & 0.033 & 0.325 & 22.1 & 24.0 & 0.112 & 0.067 & 45.2 \\
\hline \multicolumn{10}{|l|}{ North Pacific - DSDP 465A } \\
\hline \multirow[t]{2}{*}{ DSDP 465A 3-3 123-124 CT1 } & 62.4 & 12.7 & 1.08 & 27.2 & 117 & 90.1 & 9.41 & 0.085 & 9.18 \\
\hline & \multicolumn{9}{|c|}{ Hemipelagic } \\
\hline \multicolumn{10}{|l|}{ Stevns Klint, Denmark } \\
\hline SK10 CT1 & & 50.9 & 32.2 & 62.8 & 76.4 & 44.7 & 8.30 & 0.633 & 1.5 \\
\hline SK10 (Kyte et al. 1985) & & 47.4 & 35 & & 78 & 46 & 9.4 & 0.738 & 1.6 \\
\hline \multicolumn{10}{|l|}{ Caravaca, Spain } \\
\hline SM503 CT1 & & 42.0 & 31.6 & 53.7 & 85.9 & 72.4 & 1.80 & 0.752 & 2.0 \\
\hline SM503 (Kyte et al. 1985) & & 56.9 & 46 & & 131 & 110 & 2.7 & 0.808 & 2.3 \\
\hline
\end{tabular}

${ }^{\text {a }}$ Concentrations are based on dry weight; mbsf = meters below sediment-water interface; duplicates were not run in all cases; SM503 represents a thin $(\sim 1 \mathrm{~mm})$ sanidine-spherule-rich boundary clay.

width of the Re-PGE anomaly $(\sim 1.8 \mathrm{~m})$. However, because of the high baseline levels for $\mathrm{Pt}$ and $\mathrm{Pd}$, the integrated $\mathrm{Pt} / \mathrm{Ir}(0.7$ $\left.\times(\mathrm{Pt} / \mathrm{Ir})_{\mathrm{CI}}\right)$ and $\mathrm{Pd} / \mathrm{Ir}$ ratios $\left(0.4 \times(\mathrm{Pd} / \mathrm{Ir})_{\mathrm{Cl}}\right)$ are subchondritic, indicating that the apparent chondritic $\mathrm{Pt} / \mathrm{Ir}$ and $\mathrm{Pd} / \mathrm{Ir}$ ratios at the peak may be fortuitous.

Up-section from the KTB, the Re-PGE relative abundances are also fractionated from chondritic values. Pt/Ir (14 to $47 \times$ $\left.(\mathrm{Pt} / \mathrm{Ir})_{\mathrm{Cl}}\right)$ and $\mathrm{Pd} / \mathrm{Ir}$ ratios $\left(2\right.$ to $\left.42 \times(\mathrm{Pd} / \mathrm{Ir})_{\mathrm{Cl}}\right)$ are distinctly elevated compared with chondrite. Os/Ir ratios remain subchondritic throughout the upper part of the section rising from 0.08 $\times(\mathrm{Os} / \mathrm{Ir})_{\mathrm{Cl}}$ at $\sim 20 \mathrm{~m}$ below the sediment-seawater interface to $0.43 \times(\mathrm{Os} / \mathrm{Ir})_{\mathrm{Cr}}$ at $\sim 2 \mathrm{~m}$ below the sediment-seawater interface (Fig. 4). The rise in PGE abundance, particularly in Pt abundance, at $16.31 \mathrm{mbsf}$ coincides exactly with a rise in cobalt content, as determined by Zhou and Kyte (1992).

\subsection{2. $D S D P 465 A$}

Table 1 shows the dry weight Re-PGE concentrations determined for the thin reduced layer marking the KTB at the pelagic DSDP 465A. Our concentration determinations are consistent with those of Kyte et al. (1996). Chondrite-normalized values are plotted in Figure 3B. Relative to chondritic proportions, $\mathrm{Pt}, \mathrm{Pd}$, and $\mathrm{Re}$ are highly enriched relative to $\mathrm{Ir}$ $\left(\mathrm{Pt} / \mathrm{Ir}=3.2 \times(\mathrm{Pt} / \mathrm{Ir})_{\mathrm{Cl}} ; \mathrm{Pd} / \mathrm{Ir}=4.6 \times(\mathrm{Pd} / \mathrm{Ir})_{\mathrm{Cl}} ; \mathrm{Re} / \mathrm{Ir}=8.4 \times\right.$ $\left.(\mathrm{Re} / \mathrm{Ir})_{\mathrm{CI}}\right)$. The $\mathrm{Ru} / \mathrm{Ir}$ ratio is only slightly superchondritic (1.4 $\left.\times(\mathrm{Ru} / \mathrm{Ir})_{\mathrm{Cl}}\right)$. These large enrichments in $\mathrm{Pt}, \mathrm{Pd}$, and $\mathrm{Re}$, and moderate enrichment in $\mathrm{Ru}$, contrast with the lack of large enrichments seen in the integrated KTB composition at DSDP 596. As we did not measure samples above and below the KTB, we are unable to estimate the magnitude of the "baseline" contribution of $\mathrm{Pt}, \mathrm{Pd}$, and Re to the KTB at DSDP 465A. The one feature in common between $465 \mathrm{~A}$ and 596 is their distinctly subchondritic Os/Ir ratios; the Os/Ir ratio of the reduced layer at $465 \mathrm{~A}$ is $0.09 \times(\mathrm{Os} / \mathrm{Ir})_{\mathrm{CI}}$. Considering the high Os and Ir contents, we consider the Os/Ir ratio of the $465 \mathrm{~A}$ boundary clay to be robust.

\subsection{Hemipelagic Sites}

\subsubsection{Caravaca}

The Re-PGE concentrations (Table 1 and Fig. 3C) obtained for sample SM503 are $\sim 33 \%$ lower than that of Kyte et al. (1985) on similar samples, but the relative abundances are in very good agreement. The discrepancy is most likely due to sample heterogeneity. Caravaca differs from the pelagic DSDP sites in having roughly chondritic $\mathrm{PGE}$ relative abundances $\left(\mathrm{Pt} / \mathrm{Ir}=0.9 \times(\mathrm{Pt} / \mathrm{Ir})_{\mathrm{Cl}}, \mathrm{Pd} / \mathrm{Ir}=1.1 \times(\mathrm{Pd} / \mathrm{Ir})_{\mathrm{Cl}}, \mathrm{Ru} / \mathrm{Ir}=0.8 \times\right.$ $\left.(\mathrm{Ru} / \mathrm{Ir})_{\mathrm{Cl}} ; \mathrm{Os} / \mathrm{Ir}=0.8 \times(\mathrm{Os} / \mathrm{Ir})_{\mathrm{Cl}}\right)$ and a subchondritic $\mathrm{Re} / \mathrm{Ir}$ ratio $\left(0.5 \times(\mathrm{Re} / \mathrm{Ir})_{\mathrm{CI}}\right)$. Although we did not measure above and below the boundary clay, Kyte et al. (1985) reported declining PGE abundances in the $3 \mathrm{~cm}$ immediately above SM503 and low concentrations in background samples above and below the 


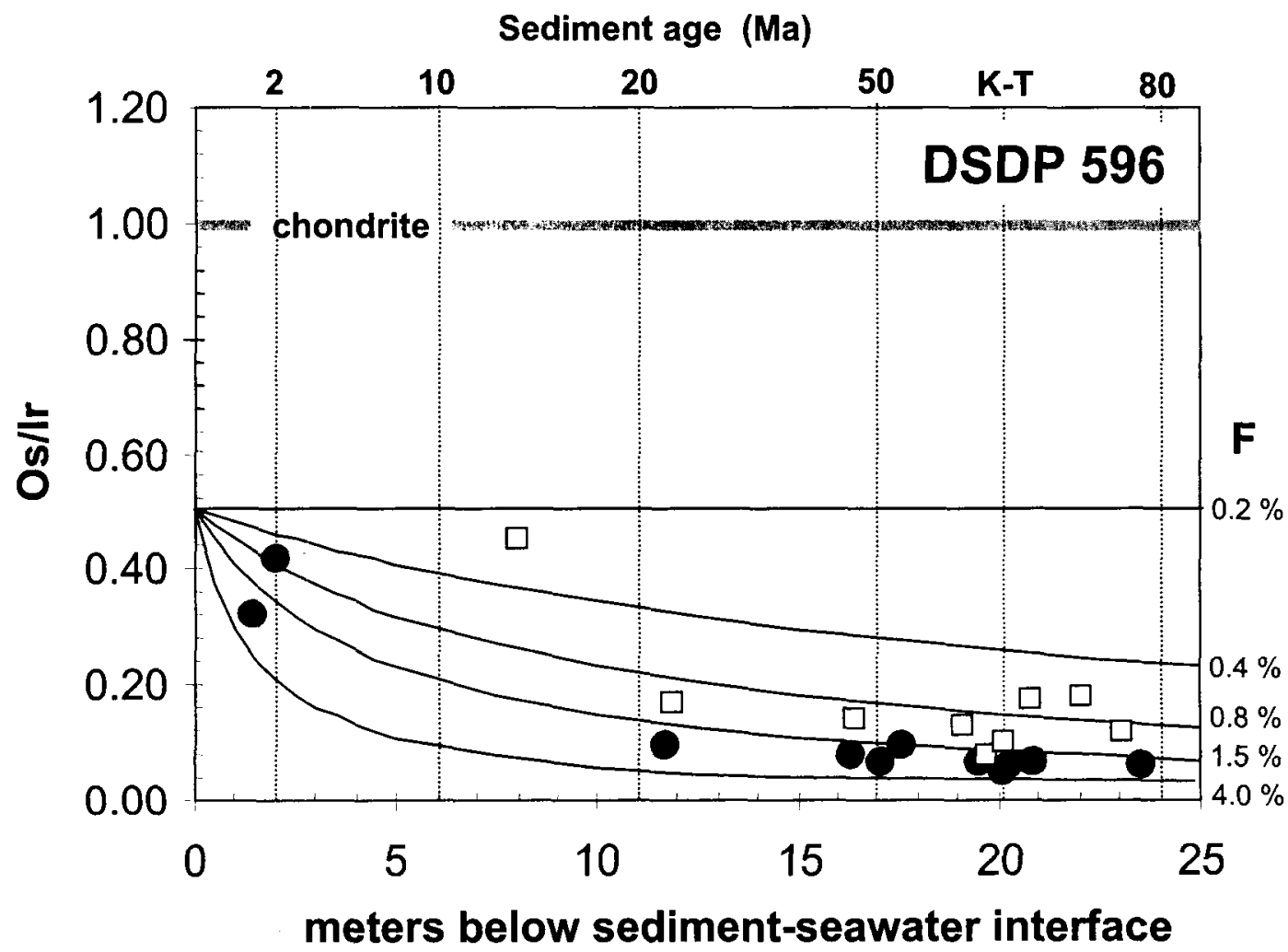

Fig. 4. Os/Ir ratios from this study (circles) vs. mbsf in DSDP 596 core. Squares represent the combined Ir and Os measurements of Zhou and Kyte (1992) and Peucker-Ehrenbrink (1996), respectively (thick horizontal line $=$ chondritic Os/Ir ratio). Upper horizontal axis provides approximate age (Ma) of sediment (Zhou and Kyte, 1992). Curves represent the $\mathrm{Os} / \mathrm{Ir}$ ratio in pelagic sediments as a function of a change in the area fraction $(\mathrm{F})$ of anoxic sediment deposition. From bottom to top. each curve represents a linear decrease from $F=0.2 \%$ at the present sediment-seawater interface to $F=4.0,1.5$, $0.8,0.4$, and $0.2 \%$, respectively, at $25 \mathrm{mbsf}$. These calculations are based on Eqn. $6 \mathrm{a}$, with $33 \mathrm{pg} / \mathrm{m}^{2} \mathrm{yr}$ used as the value for the pelagic Os burial flux (Table 4), $1.5 \times 10^{5} \mathrm{pg} / \mathrm{m}^{2} \mathrm{yr}$ for the anoxic Os burial flux, and the riverine Os/Ir ratio given in Table 2.

KTB. They found that Os/Ir ratios actually decline somewhat in PGE-rich sediments above SM503, but only to ratios $\sim 50 \%$ lower than in chondrites. They did not observe the extremely low Os/Ir ratios seen here in pelagic sites.

\subsubsection{Stevns Klint}

Re-PGE abundances for the boundary clay from the hemipelagic Stevns Klint section are shown in Table 1 and chondritenormalized abundances are shown in Figure 4d. PGE abundances agree to within $10 \%$ and $\operatorname{Re}$ abundances to within $15 \%$ of Kyte et al. (1985). Considering that the samples were processed separately, this is remarkable agreement. Except for Re, the PGE abundances have near-chondritic proportions $(\mathrm{Pt} / \mathrm{Ir}=$ $1.5 \times(\mathrm{Pt} / \mathrm{Ir})_{\mathrm{Cl}}, \mathrm{Pd} / \mathrm{Ir}=0.9 \times(\mathrm{Pd} / \mathrm{Ir})_{\mathrm{Cl}}, \mathrm{Ru} / \mathrm{Ir}=1.2 \times$ $\left.(\mathrm{Ru} / \mathrm{Ir})_{\mathrm{Cl}} ; \mathrm{Os} / \mathrm{Ir}=0.7 \times(\mathrm{Os} / \mathrm{Ir})_{\mathrm{Cl}}\right)$, and therefore Stevns Klint resembles Caravaca. Re is somewhat elevated with respect to $\mathrm{Ir}$ $\left(1.9 \times(\mathrm{Re} / \mathrm{lr})_{\mathrm{Cl}}\right)$. We did not measure above and below the boundary clay, but given the high peak concentration, it is likely that any baseline levels of Re-PGEs are comparably small.

\section{DISCUSSION}

We first discuss the origin of the broad $(\sim 1.8 \mathrm{~m}) \mathrm{Re}, \mathrm{Pt}, \mathrm{Ir}$, Os, and Ru anomaly at DSDP 596 (Fig. 2). This depth interval corresponds to an apparent deposition time of $\sim 6 \mathrm{Ma}$ (based on a constant sedimentation rate), which is much too long to be reconciled with the fallout of a single impact event and therefore requires postdepositional Re-PGE redistribution in the stratigraphic column. We will also discuss the origin of the high degree of Re-PGE fractionation in the two pelagic sites compared with the two hemipelagic sites, in particular, focusing on the origin of the extremely low Os/Ir ratios in the two pelagic sites.

\subsection{Causes of Postdepositional Re-PGE Mobilization at DSDP 596}

One way to obtain a symmetric profile for Re, Pt, Ir, Os, and $\mathrm{Ru}$ is by diffusional redistribution of an initial spike in PGE, mathematically represented by

$$
C=\left(\frac{C_{T}}{\rho \sqrt{4 \pi D t}}\right) e^{-\Delta r^{2} /(4 D t)}
$$

where $C$ is the concentration (after subtraction of the back- 
spherules: Stratigraphy, age and geochemistry. Meteoritics 22, 2560.

Koide M., Goldberg E. D., Niemeyer S., Gerlach D,, Hodge V., Bertine K. K., and Padova A. (1991) Osmium in marine sediments. Geochim. Cosmochim. Acta 55, 1641-1648.

Kyte F. T., Smit J., and Wasson J. T. (1985) Siderophile interelement variations in the Cretaceous-Tertiary boundary sediments from Caravaca, Spain. Earth Planet. Sci. Lett. 73, 183-195.

Kyte F. T., Leinen M., Heath G. R., and Zhou L. (1993) Cenozoic sedimentation history of the central North Pacific: Inferences from the elemental geochemistry of core LL44-GPC3. Geochim. Cosmochim. Acta 57, 1719-1740.

Kyte F. T., Bostwick J. A., and Zhou L. (1996) The CretaceousTertiary boundary on the Pacific plate: Composition and distribution of impact debris. Geol. Soc. Am. Spec. Paper 307, 389-401.

Larimer J. W. and Wasson J. T.(1988) Siderophile element fractionation. In Meteorites and the Early Solar System (ed. J. F. Kerridge and M. S. Matthews), pp. 416-435. University of Arizona Press.

Lee C-T. A. (2002) Platinum-group element geochemistry of peridotite xenoliths from the Sierra Nevada and the Basin and Range, California. Geochim. Cosmochim. Acta 66, 3987-4005.

Lee C.-T., Yin Q.-Z., and Lee T.-C. (2001) An internal normalization technique for unmixing total-spiked mixtures with application to MC-ICP-MS. Comp. Geosci. 27, 577-581.

Levasseur S., Birck J.-L., and Allegre C. J. (1998) Direct measurement of femtomoles of osmium and the ${ }^{187} \mathrm{Os} /{ }^{188} \mathrm{Os}$ ratio in seawater. Science 282, 272-274.

Levasseur S., Birck J.-L., and Allegre C. J. (1999) The osmium riverine flux and the oceanic mass balance of osmium. Earth Planet. Sci. Lett. $174,7-23$.

Levasseur S., Rachold V., Birck J.-L., and Allegre C. J. (2000) Osmium behaviour in estuaries: The Lena River example. Earth Planet. Sci. Lett. 177, 227-235.

Lowemark L. and Werner F. (2001) Dating errors in high-resolution stratigraphy: A detailed X-ray radiograph and $\mathrm{AMS}-{ }^{14} \mathrm{C}$ study of Zoophycosburrows. Mar. Geol. 2001, 191-198.

Martin C. E., Peucker-Ehrenbrink B., Brunskill G. J., and Szymczak R. (2000) Sources and sinks of unradiogenic osmium runoff from Papua New Guinea. Earth Planet. Sci. Lett. 183, 261-274.

Martin C. E., Peucker-Ehrenbrink B., Brunskill G., and Szymczak R. (2001) Osmium isotope geochemistry of a tropical estuary. Geochim. Cosmochim. Acta 65, 3193-3200.

McDuff R. E. (1981) Major cation gradients in DSDP interstitial waters: The role of diffusive exchange between seawater and upper oceanic crust. Geochim. Cosmochim. Acta 45, 1705-1713.

Michel G. R., Asaro F., Alvarez W., and Alvarez L. W. (1985) Elemental profile of iridium and other elements near the Cretaceous/ Tertiary boundary in Hole 577B. In Initial Reports: DSDP86 (eds. G. R. Heath, et al.),Vol. 86, pp. 533-538. U.S. Government Printing Office.

Morford J. L. and Emerson S. (1999) The geochemistry of redox sensitive trace metals in sediments. Geochim. Cosmochim. Acta 63, $1735-1750$.

Opdyke B. N. and Wilkinson B. H. (1988) Surface area control of shallow cratonic to deep marine carbonate accumulation. Paleoceanography 3, 685-703.

Pearson D. G., Woodland S. J., Sigurdsson H., Shirey S. B., Murray R. W., Lyons T. W., and Schmitz B. (1999) Os isotopes and platinum group elements in K-T boundary clays: Impact signatures versus post-impact processes. Geol. Soc. Am. Abstr. Programs 31, 123-124.

Pegram W. J., Krishnaswami S., Ravizza G. E., and Turekian K. K. (1992) The record of sea water ${ }^{187} \mathrm{Os} /{ }^{186} \mathrm{Os}$ variation through the Cenozoic. Earth Planet. Sci. Lett. 113, 569-576.

Pegram W. J. and Turekian K. K. (1999) The osmium isotopic composition change of Cenozoic sea water as inferred from a deep-sea core corrected for meteoritic contributions. Geochim. Cosmochim. Acta 63, 4053-4058.

Peucker-Ehrenbrink B. (1996) Accretion of extraterrestrial matter during the last 80 million years and its effect on the marine osmium isotope record. Geochim. Cosmochim. Acta 60, 3187-3196.

Peucker-Ehrenbrink B., Ravizza G., and Hofmann A. W. (1995) The marine ${ }^{187} \mathrm{Os} /{ }^{186} \mathrm{Os}$ record of the past 80 million years. Earth Planet. Sci. Lett. 130, 155-167.

Peucker-Ehrenbrink B. and Hannigan R. E. (2000) Effects of black shale weathering on the mobility of rhenium and platinum group elements. Geology 28, 475-478.

Peucker-Ehrenbrink B. and Ravizza G. (2000) The marine osmium isotope record. Terra Nova 12, 205-219.

Peucker-Ehrenbrink B. and Jahn B.-M. (2001) Rhenium-osmium isotope systematics and platinum group element concentrations: Loess and the upper continental crust. Geochm. Geophys. Geosys. 2, 2001 GC000172.

Ravizza G. and Turekian K. K. (1992) The osmium isotopic composition of organic-rich marine sediments. Earth Planet. Sci. Lett. 110, $1-6$

Ravizza G. and Pyle D. (1997) PGE and Os isotopic analysis of single sample aliquots with NiS fire assay preconcentration. Chem. Geol. 141, 251-268.

Ravizza G., Blusztajn J., and Prichard H. M. (2001) Re-Os systematics and platinum-group element distribution in metalliferous sediments from the Troodos ophiolite. Earth Planet. Sci. Lett. 188, 369-381.

Robin E., Boclet D., Bonte P., Froget L., Jehanno C., and Rocchia R. (1991) The stratigraphic distribution of Ni-rich spinels in Cretaceous-Tertiary boundary rocks at El Kef, (Tunisia), Caravaca (Spain) and Hole 761C (Leg 122). Earth Planet. Sci. Lett. 107, 715-721.

Sharma M. and Wasserburg G. J. (1997) Osmium in rivers. Geochim. Cosmochim. Acta 61, 5411-5416.

Sharma M., Wasserburg G. J., Hofmann A. W., and Chakrapani G. J. (1999) Himalayan uplift and osmium isotopes in oceans and rivers. Geochim. Cosmochim. Acta 63, 4005-4012.

Sharma M., Wasserburg G. J., Hofmann A. W., and Butterfield D. A. (2000) Osmium isotopes in hydrothermal fluids from the Juan de Fuca Ridge. Earth Planet. Sci. Lett. 179, 139-152.

Shirey S. B. and Walker R. J. (1995) Carius tube digestion for lowblank rhenium-osmium analysis. Anal. Chem. 67, 2136-2141.

Shukolyukov A. and Lugmair G. W. (1998) Isotopic evidence for the Cretaceous-Tertiary impactor and its type. Science 282, 927-929.

Smit J. and Hertogen J. (1980) An extra-terrestrial event at the Cretaceous-Tertiary boundary. Nature 285, 198-200.

Thiede J., et al. (1992) Initial Reports of the Deep Sea Drilling Project. U.S. Government Printing Office.

Thomson J., Brown L., Nixon S., Cook G. T., and MacKenzie A. B. (2000) Bioturbation and. Holocene sediment accumulation fluxes in the north-east Atlantic Ocean (Benthick Boundary Layer experiment sites). Mar. Geol. 169, 21-39.

Woodwell G. M., Rich P. H., and Hall C. A. S. (1973) Carbon in estuaries. Brookhaven Symp. Biol. Series, (eds. G. M. Woodwell and E. V. Pecan) pp. 221-224. Brookhaven National Laboratory, Upton, New York.

Yin Q. Z., Jacobsen S. B., Lee C.-T., McDonough W. F., Rudnick R. L., and Horn I. (2001) A gravimetric $\mathrm{K}_{2} \mathrm{OsCl}_{6}$ standard: Application to precise and accurate Os spike calibration. Geochim. Cosmochim. Acta 65, 2113-2127.

Zhou L., Kyte F. T., and Bohor B. F. (1991) Cretaceous/Tertiary boundary of DSDP Site 596, South Pacific. Geology 19, 694-697.

Zhou L. and Kyte F. (1992) Sedimentation history of the South Pacific pelagic clay province over the last 85 million years inferred from the geochemistry of Deep Sea Drilling Project Hole 596. Paleoceanography $7,441-465$. 
from $2 \times 10^{2}$ to $2 \times 10^{4} \mathrm{yr}$, for Os ranges from $1 \times 10^{5}$ to 6 $\times 10^{6} \mathrm{yr}$, and for Re ranges from $2 \times 10^{8}$ to $1 \times 10^{9} \mathrm{yr}$. The large discrepancies between residence times calculated from the riverine input $\left(\tau_{2 A}\right)$ and the pelagic burial output $\left(\tau_{2 B}\right)$ reflects the fact that $O s$ and $R e$ are primarily being sequestered in other sinks besides the deep sea. The high Os and Re $\tau_{2 B} \mathrm{~s}$, however, appear to be geologically unreasonable, suggesting that oceanic margins, rather than estuaries, represent the other sink for Os and Re. The similarity between $\tau_{2 B}$ and $\tau_{2 A}$ for Ir $\left(\sim 2 \times 10^{3} \mathrm{yr}\right.$; Table 2$)$ is consistent with pelagic sediments representing the main sink for Ir input into the ocean.

Finally, there is also the possibility that Os and Re can be removed from seawater when it returns to the estuary (Martin et al., 2001). In the extreme case, when only seawater Os is removed and no riverine $\mathrm{Os}$ is removed, the oceanic residence times would remain unchanged from scenario $\mathrm{A}$.

\section{CONCLUSIONS}

The nature of Re-PGE transport in the marine environment was investigated by using marine sediments at and across the KTB at two hemipelagic and two pelagic sites. A traverse across the KTB in a Pacific pelagic clay core found elevated levels of Re, Pt, Ir, Os, and Ru, each of which is approximately symmetrically distributed over a distance of $\sim 1.8 \mathrm{~m}$ across the KTB. The 1.8-m interval containing the Re-PGE anomaly cannot be reconciled with the fallout of a single impactor with chondritic abundances, indicating that postdepositional redistribution has occurred. If the elemental profiles are the result of diffusion that occurred over $\sim 65 \mathrm{Ma}$, then the effective diffusivities are $\sim 10^{-13} \mathrm{~cm}^{2} / \mathrm{s}$, much smaller than that of soluble cations in pore waters $\left(\sim 10^{-6} \mathrm{~cm}^{2} / \mathrm{s}\right)$. Regardless of the cause of redistribution, the fact that Re and the PGEs are spread out over the same lengthscale indicates that postdepositional processes did not significantly fractionate their relative abundances. If redistribution was caused by diffusion, then effective diffusivities of Re and the PGEs must be equal. The Re-PGE abundance patterns are fractionated from chondritic relative abundances, both at the KTB and integrated over the whole section. Os is depleted by $\sim 95 \%$ relative to chondritic Ir at the pelagic KTB in the South Pacific. A similar depletion in Os was found in a sample from another pelagic KTB section in the North Pacific. However, the two hemipelagic KTB clays have near-chondritic abundance patterns. Because the fractionations seen in the pelagic sections predate deposition, fractionation of Os from Ir during the KTB interval must have occurred during aqueous transport in the marine environment. Extremely subchondritic Os/Ir ratios throughout the Cenozoic in the pelagic South Pacific section further suggest that fractionation of Os from Ir in the marine environment is a general process throughout geologic time because most of the inputs of Os and Ir into the ocean have Os/Ir ratios $\geq 1$.

The generality of this process is confirmed by a global mass balance calculation, which shows that pelagic Os and Re burial fluxes account for only a small fraction of the Os $(<10 \%)$ and $\operatorname{Re}(<0.1 \%)$ riverine inputs into the ocean while Ir burial in pelagic sediments appears to be a major sink for $\mathrm{Ir}$ in the oceans. If all of the missing $\mathrm{Os}$ and $\mathrm{Re}$ is assumed to reside in anoxic sediments in oceanic margins instead of pelagic sediments, then the respective burial fluxes calculated by mass balance for these sediments is comparable to observed values of Os and Re in organic-rich sediments in oceanic margins. In contrast, putting all of the missing Os and Re into estuarine sediments would require high concentrations to balance the riverine input and would also fail to explain the depletion of Os at pelagic KTB sites, where at most $\sim 25 \%$ (the area of land surface) of the K-T impactor's Os could have passed through estuaries. There is thus a clear fractionation of Os and Re from Ir in precipitation out of sea water in pelagic sections. Accordingly, it is inferred here that Re and Os are removed from sea water in anoxic marine depositional regimes. If $\mathrm{Os}$ is preferentially sequestered in anoxic marine environments, then the Os/Ir ratio of pelagic sediments should be sensitive to changes in the rates and areas of anoxic sediment deposition.

Acknowledgments-Diane McDaniel, Thomas Meisel, associate editor R. Walker, and an anonymous reviewer are thanked for reviews. Discussions with James Chen, Jerome Gaillardet, Damien LeMarchand, Graham Pearson, and Bernhard Peucker-Ehrenbrink are appreciated. Samples from DSDP 465 and DSDP 596 were supplied by Ocean Drilling Program, which is curated with support from the National Science Foundation. Samples SK10 and SM503 were collected and supplied by J. Smit. This study was supported by DOE DF FG0388ER13851. This is Caltech contribution 8894 (1096).

Associate editor: R. Walker

\section{REFERENCES}

Alvarez L. W., Alvarez W., Asaro F., and Michel H. V. (1980) Extraterrestrial cause for the Cretaceous-Tertiary extinction. Science 208, $1095-1108$.

Anbar A. D., Creaser R. A., Papanastassiou D. A., and Wasserburg G. J. (1992) Rhenium in seawater: Confirmation of generally conservative behavior. Geochim. Cosmochim. Acta 56, 4099-4103.

Anbar A. D., Wasserburg G. J., Papanastassiou D. A., and Andersson P. S. (1996) Iridium in natural waters. Science 273, 1524-1528.

Anders E. and Grevesse N. (1989) Abundances of the elements: Meteoritic and solar. Geochim. Cosmochim. Acta 53, 197-214.

Berger W. H. and Heath G. R. (1968) Vertical mixing in pelagic sediments. J. Mar. Res. 26, 134-143.

Boersma A.(1981) Cretaceous and early Tertiary foraminifers from deep sea drilling project Leg 62 sites in the central Pacific. In Initial Reports of the Deep Sea Drilling Program, Vol. 62, pp. 377-396. U.S. Government Printing Office.

Broecker W. S. and Li Y.-H. (1970) Interchange of water between the major oceans. J. Geophys. Res. 75, 3545-3552.

Brownlee D. E., Bates B. A., and Wheelock M. M. (1984) Extraterrestrial platinum group nuggets in deep-sea sediments. Nature $\mathbf{3 0 9}$, 693-695.

Colodner D., Sachs J., Ravizza G., Turekian K., Edmond J., and Boyle E. (1993) The geochemical cycle of rhenium: A reconnaissance. Earth Planet. Sci. Lett. 117, 205-221.

Crank J. (1975) The Mathematics of Diffusion. Oxford University Press.

Crusius J., Calvert S., Pedersen T., and Sage D. (1996) Rhenium and molybdenum enrichments in sediments as indicators of oxic, suboxic and sulfidic conditions of deposition. Earth Planet. Sci. Lett. 145, 65-78.

Davies T. A. and Gorsline D. S.(1976) Oceanic sediments and sedimentary processes. In Chemical Oceanography (eds. J. P. Riley and R. Chester), Vol. 5, pp. 1-80. Academic Press.

Kastner M., Asaro F., Michel H. V., Alvarez W., and Alvarez L. W. (1984) The precursor of the Cretaceous-Tertiary boundary clays at Stevns Klint, Denmark, and DSDP Hole 465A. Science 226, 137143.

Keller G., D'Hondt S. L., Orth C. J., Gilmore J. S., Oliver P. Q., Shoemaker E. M., and Molina E. (1987) Late Eocene impact micro- 


$$
\frac{C_{4}^{O s}}{C_{4}^{l r}}=\left(\frac{C_{0}^{O s}}{C_{0}^{\prime r}}\right)\left(\frac{1+\beta^{O s}}{1+\beta^{l r}}\right) \frac{\left(\rho_{3} \alpha_{23} C_{3}^{I r} / \rho_{4} \alpha_{24} C_{4}^{I r}\right) F+(1-F)}{\left(\rho_{3} \alpha_{23} C_{3}^{O s} / \rho_{4} \alpha_{24} C_{4}^{O s}\right) F+(1-F)}
$$

Eqn. 6a depends on the Os/Ir ratio of the riverine input rather than the absolute Os and Ir concentrations in rivers. Taking $\beta^{\text {Os }}$ and $\beta^{\text {Ir }}$ to be $\sim 0.2$ (Sharma et al., 1999) and the removal rate of $\mathrm{Ir}$ by anoxic sediments is negligible (e.g., $\rho_{3} \alpha_{23} C_{3}^{I r}$ / $\left.\rho_{4} \alpha_{24} \mathrm{C}_{4}^{\prime r}\right)<<1$ ), Eqn. 6a simplifies to

$$
\frac{C_{4}^{O s}}{C_{4}^{l r}} \sim\left(\frac{C_{0}^{O_{s}}}{C_{0}^{l r}}\right) \frac{(1-F)}{\left(\rho_{3} \alpha_{23} C_{3}^{O s} / \rho_{4} \alpha_{24} C_{4}^{O s}\right) F+(1-F)}
$$

Thus, when the area fraction of anoxic sediments is negligible $(\mathrm{F}=0)$, the Os/Ir ratio of pelagic sediments is equal to the riverine Os/Ir ratio. When $F$ approaches 1, the Os/Ir ratio of pelagic sediments approaches zero. Because of the strong affinity of Os for anoxic sediments, only a very small amount of anoxic sediment deposition is needed to decrease the Os/Ir ratio of pelagic sediments. It follows that a shift in Os/Ir ratio of 0.06 to 0.4 in the upper part of the DSDP 596 section may simply reflect a decrease in deposition of anoxic sediments. We have illustrated in Figure 3 how a decrease with age in the area of anoxic sediment deposition, $\mathrm{F}$, from $\sim 1.5 \%$ at $\sim 80 \mathrm{Ma}$ to $0.2 \%$ today can reproduce the pattern of Os/Ir ratios in the DSDP 596 section, for the case in which $\rho_{3} \alpha_{23} C_{3}^{O s} / \rho_{4} \alpha_{24} C_{4}^{O s}$ and the Os/Ir ratio of the rivers remain constant and $\beta^{\mathrm{Os}} / \beta^{\mathrm{Ir}} \sim 1$. Because Re also has a high affinity for anoxic marine sediments, variations in rates of anoxic/suboxic sediment deposition should lead to covariations in $\mathrm{Re} / \mathrm{Ir}$ and $\mathrm{Os} / \mathrm{Ir}$ ratios. $\mathrm{Re} / \mathrm{Ir}$ ratios in DSDP 596 indeed show an increase with decreasing depth below the sediment-seawater interface. It is possible that variations in anoxic sediment deposition may also control the shifts in other PGEs seen in DSDP 596.

If the Os and Ir in the upper part of the DSDP 596 core are not directly derived from seawater but are instead derived from a continental detrital component with $\mathrm{Os} / \mathrm{Ir}>1$, the increase in Os/Ir ratios from $<0.1$ to $\sim 0.4$ could be due to an increase in detrital proportion rather than reflecting changes in seawater composition. As the concentration of Ir in the upper $\sim 2 \mathrm{~m}$ of the DSDP 596 section is $\sim 300 \mathrm{pg} / \mathrm{g}$ (Table 1), a detrital component corresponding to $\sim 100 \mathrm{pg} / \mathrm{g} \mathrm{Ir}$ and $\sim 100 \mathrm{pg} / \mathrm{g}$ Os is needed to increase the $\mathrm{Os} / \mathrm{Ir}$ ratio of the sediment from 0.1 to 0.4 . These values are much higher than the Os and Ir concentrations of upper continental crust ( $\sim 22 \mathrm{pg} / \mathrm{g}$ Ir and $\sim 31 \mathrm{pg} / \mathrm{g}$ Os; Peucker-Ehrenbrink and Jahn, 2001). Thus, although the sedimentation rates in the DSDP 596 core appear to have increased with younging age (Zhou and Kyte, 1992), the above calculation shows that the Os/Ir ratios in these sediments predominantly reflect seawater and not the detrital component.

\subsection{Further Implications}

Understanding the transport properties of Re and the PGEs in the marine and estuarine environments has important implications for calculating their residence times in the ocean, that is the average amount of time the element of interest resides in the ocean. For the case in which there is no removal of an element in estuaries (scenario A; Fig. 7A), the inverse of the element's oceanic residence time, $\tau_{2 A}$, can be expressed as

$$
\frac{1}{\tau_{2 A}}=(1+\beta) \frac{Q_{02} C_{0}}{M_{2} C_{2}}=\frac{Q_{23} C_{3}}{M_{2} C_{2}}+\frac{Q_{24} C_{4}}{M_{2} C_{2}},
$$

where $\mathrm{M}_{2}$ is the mass of the ocean, $\mathrm{C}_{2}$ is the concentration of the element of interest in the ocean, and all other symbols are previously defined. Eqn. 7 shows that the inverse of the oceanic residence time, for the case in which removal is completely within the oceans, is equal to the summation of the rate constants for deposition in the oceanic sinks or to the rate constant of the riverine input. In most cases, the residence time is calculated from the latter because the total of all the oceanic sinks is not well known. Assuming $\beta$ is small ( $\beta \sim 0.2$; Sharma et al., 1999), estimates of the riverine Re-PGE input and the Re-PGE concentration in seawater (Table 2) can be used to calculate $\tau_{2 A}$ in this manner. This yields $2 \times 10^{3}, 4 \times 10^{4}$, and $7 \times 10^{3} \mathrm{yr}$ for the oceanic residence time of Ir, Os, and Re, respectively. These values are in accord with previous studies in which estuarine removal was also considered to be small or zero (Anbar et al., 1992, 1996; Colodner et al., 1993; Sharma and Wasserburg, 1997; Levasseur et al., 1999; Sharma et al., 1999). If the dominant removal process of Ir, Os, and Re is within the oceans instead of the estuaries, then the burial flux in oceanic margins $\mathrm{Q}_{24} \mathrm{C}_{4}$ can be calculated from the known pelagic burial and riverine input fluxes.

On the other hand, if removal occurs in the estuaries and in only one oceanic sink (scenario B; Fig. 7B), the residence time is fundamentally changed. The inverse of the oceanic residence time $\tau_{2 B}$ is expressed as

$$
\frac{1}{\tau_{2 B}}=\left(1-f_{13}+\beta\right) \frac{Q_{01} C_{0}}{M_{2} C_{2}}=\frac{Q_{24} C_{4}}{M_{2} C_{2}}
$$

where $f_{13}$ is the fractional removal of riverine flow in the estuary and all other symbols are previously defined. Because $Q_{01} C_{0}$ in scenario $B$ is equivalent to $Q_{02} C_{0}$ in scenario $A$, Eqn. 8 can be reexpressed to yield the scenario $B$ oceanic residence time, $\tau_{2 B}$, in terms of the scenario A residence time, $\tau_{2 A}$ :

$$
\tau_{2 B}=\frac{(1+\beta) \tau_{2 A}}{(1+\beta)-f_{13}}
$$

Because $\beta$ is small, Eqn. 9a simplifies to the approximation

$$
\tau_{2 B} \sim \frac{\tau_{2 A}}{1-f_{13}}
$$

Thus, if estuarine removal occurs, the residence time calculated assuming transport processes described by scenario A (Eqn. 7) must be increased by a factor of $1 /\left(1-f_{13}\right)$. For example, if $>90 \%$ and $>99.9 \%$ of the riverine $\mathrm{Os}$ and $\mathrm{Re}$, respectively, are sequestered in estuaries, scenario $B$ residence times for Os and Re will be orders of magnitude higher, i.e., $5 \times 10^{5}$ and $7 \times$ $10^{6} \mathrm{yr}$ (scenario B) instead of $5 \times 10^{4}$ and $7 \times 10^{3} \mathrm{yr}$ (scenario A), respectively. As the fraction of riverine component removed in estuaries, $f_{13}$, is not known very well, scenario $B$ oceanic residence times $\left(\tau_{2 B}\right)$ can be calculated from pelagic burial fluxes (right-hand side of Eqn. 8) because these sediments represent the only oceanic sink in scenario B. Scenario B residence times $\left(\tau_{2 B}\right)$ for $\mathrm{Ir}$, Os, and Re calculated in this manner are shown in Table 3 along with the pelagic burial flux estimates used in the calculations. We find that $\tau_{2 B}$ for Ir ranges 
at least $1.4 \times 10^{7} \mathrm{pg} / \mathrm{m}^{2} \mathrm{yr}$. These oceanic margin burial fluxes for Os and Re are roughly in agreement with direct estimates of the Os $\left(6\right.$ to $\left.12 \times 10^{4} \mathrm{pg} / \mathrm{m}^{2} \mathrm{yr}\right)$ and $\operatorname{Re}\left(1.6 \times 10^{7} \mathrm{pg} / \mathrm{m}^{2} \mathrm{yr}\right)$ burial fluxes in organic-rich sediments found in oceanic margins (Ravizza and Turekian, 1992; Colodner et al., 1993), consistent with anoxic marine sediments being a significant repository for Os and Re (Ravizza and Turekian, 1992). Superchondritic Os/Ir ratios measured on black shales (Os/Ir $\sim 4$ to 21 for the Ordovician Utica black shales in Quebec; PeuckerEhrenbrink and Hannigan, 2000), are also consistent with Os being preferentially sequestered over $\mathrm{Ir}$ in anoxic environments.

If scenario $\mathrm{A}$ is the dominant mechanism for redistributing Os and $\mathrm{Re}$ in the ocean (i.e., over $90 \%$ of oceanic Os and essentially all of the $\mathrm{Re}$ is transported from the open ocean to oceanic margins, which make up only a small fraction of the entire ocean floor), the physical plausibility of this scenario must be assessed. A minimum constraint can be placed on the mass flow of water in the oceans. Assume that a wall is placed in the ocean for scenario A, such that the deep open ocean is designated by reservoir 2 and oceanic margins, where $O$ s is sequestered (reservoir 3), is designated by reservoir 1 (Fig. 7C). The mass flow of water between reservoirs 1 and $2, Q_{12}$ and $Q_{21}$, are equal to conserve mass (assuming no differences in evaporation rate from reservoirs 1 and 2$)$. The mass balance of Os for the open ocean $\left(C_{2}\right)$ is $0=(1+\beta) Q_{02} C_{0}-Q_{24} C_{4}+$ $\mathrm{Q}_{12}\left(\mathrm{C}_{1}-\mathrm{C}_{2}\right)$. The pelagic burial flux of Os, $\mathrm{Q}_{24} \mathrm{C}_{4}$, is very small, so this equation simplifies to $\mathrm{Q}_{12}=(1+\beta)\left(\mathrm{Q}_{02} \mathrm{C}_{0}\right) /$ $\left(\mathrm{C}_{2}-\mathrm{C}_{1}\right)$. A minimum constraint on the mass flow in the ocean, $\mathrm{Q}_{12}$, is given by $Q_{12} \geq Q_{02} C_{0}(1+\beta) / C_{2}$. In the case of the modern oceans and rivers, the concentrations of Os in rivers and the open ocean are nearly equal $\left(\mathrm{C}_{0}=\mathrm{C}_{2}\right)$, and therefore, $Q_{12} \geq Q_{02}(1+\beta)$. Thus, to move nearly all of the $\mathrm{Os}$ from the deep ocean to another region in the ocean for deposition, the water flow in the ocean must be equal to or greater than the global riverine water input $\left(Q_{02}\right)$, which is $3.6 \times 10^{16} \mathrm{~kg} / \mathrm{yr}$. If it is assumed that the concentration of $O s$ in the oceans varies by no more than $\sim 10 \%$ (e.g., $\left.\left(C_{2}-C_{1}\right) / C_{0} \sim 0.1\right)$ ), then $Q_{12}$ $=3.6 \times 10^{17} \mathrm{~kg} / \mathrm{yr}$ for the case in which $\beta=0$ (it is unlikely that $\beta$ is greater than 1; Sharma et al., 1999). Taking the mixing time of water in the oceans to be $\sim 1500 \mathrm{yr}$ (Broecker and $\mathrm{Li}$, 1970), the average mass flow of water in the oceans is therefore estimated by dividing the mass of water in the oceans by the mixing time. This gives a mass flow of water in the oceans of $9 \times 10^{17} \mathrm{~kg} / \mathrm{yr}$. These calculations show that redistribution of Os completely within the oceans by ocean currents is physically plausible. The intraocean current flow rates indicated here should be sufficient to redistribute other elements in the open ocean to localized regions where they could be sequestered.

We now assess Os transport in scenario $B$ where all of the missing $O s$ is sequestered in estuaries instead of oceanic margins. If the area covered by estuaries is $\sim 3.8 \times 10^{11} \mathrm{~m}^{2}$, or $0.1 \%$ of the area of the oceans (Woodwell et al., 1973), we can use Eqn. 3, taking $\beta=0$, to calculate the minimum Os concentration of estuarine sediments given some estimate of the sediment mass accumulation rate. Martin et al. (2000) measured the Os concentration of estuarine sediments at the mouth of the Fly and Sepik rivers, which drain the island of Papua New Guinea. If we generalize the sediment mass accumulation rates reported by Martin et al. (2000), 1.5 to $15 \times 10^{3}$ $\mathrm{g} / \mathrm{m}^{2} \mathrm{yr}$, we find that estuarine sediments should have at least 50 to $500 \mathrm{pg} / \mathrm{g}$ of Os. These minimum values are slightly higher than the estuarine sediment concentrations ( $86 \pm 43 \mathrm{pg} / \mathrm{g}$; 1 SD) reported by Martin et al. (2000), suggesting that estuarine sediments may not be the dominant sink for Os. The implausibility of scenario B can also be revealed by examining Eqn. 3 . In the extreme case in which riverine Os is completely removed in estuaries, $f_{13}=1$, the ensuing requirement that $f_{24}$ $=\beta$ (Eqn. 2) would indicate that the isotopic composition of Os in seawater is governed solely by cosmic infall or hydrothermal fluxing. This is certainly not allowed as the Os isotopic composition of seawater is much more radiogenic than meteoritic and hydrothermal signatures (Sharma and Wasserburg, 1997; Levasseur et al., 1998; Sharma et al., 1999). These conclusions are further corroborated by the fact that Os/Ir ratios are extremely subchondritic at the KTB in pelagic sediments. As oceans make up $\sim 75 \%$ of the Earth's surface, at most $25 \%$ of the impactor's Re-PGE fallout could have passed through rivers and estuaries if the fallout was homogenously distributed over the Earth's surface.

We consider that Os transport is best described by scenario $A$, in which most of the Os and virtually all of the $R e$ is sequestered in oceanic margins rather than in oxic pelagic environments. Ir appears to be strongly sequestered in pelagic sediments instead of oceanic margin sediments. This implies that the Os content of pelagic sediments underestimates the extraterrestrial influx, whereas the Ir content of pelagic sediments overestimates the extraterrestrial influx (Peucker-Ehrenbrink, 1996).

\subsection{Significance of Variations in Os/Ir in Pelagic Clays}

One significant feature of the DSDP 596 core is that the Os/Ir ratio in the core sediments rises from 0.06 to 0.1 near the KTB to $\sim 0.4$ at $\sim 2 \mathrm{~m}$ below the sediment-water interface in (Fig. 4). The change in $\mathrm{Os} / \mathrm{Ir}$ ratio of pelagic sediments must be due to changes in the Os/Ir ratio of seawater. We explore the simple case in which the Os/Ir ratio of the total oceanic input is constant and the changing Os/Ir ratio of the ocean is due to changes in the deposition rates of Os and $\mathrm{Ir}$ in the ocean as a result of changes in the areal distribution of anoxic and oxic sediments. Assuming steady state, the mass balance of Os in the ocean (Fig. 7A) can be expressed as

$$
\left(1+\beta^{O s}\right) \frac{Q_{02} C_{0}^{O s}}{A}=\rho_{4} \alpha_{24} C_{4}^{O_{s}}(1-F)+\rho_{3} \alpha_{23} C_{3}^{O_{s}} F,
$$

where $A$ is the area of the seafloor, $F$ is the fraction of the total area occupied by anoxic sediments $\left[F=A_{3} /\left(A_{3}+A_{4}\right)\right]$, and all other terms are defined as before. Clearly, the concentration of Os in the sediments $C_{3}^{O s}$ and $C_{4}^{O s}$ will change for a fixed riverine input of $\mathrm{Os}\left(Q_{02} C_{4}^{O s}\right)$ if the sediment deposition rates change. It follows that changes in the area of anoxic sedimentation would cause substantial changes in the Os concentration in pelagic sediments. If Eqn. 4 is rewritten for Ir,

$$
\left(1+\beta^{l r}\right) \frac{Q_{02} C_{0}^{l r}}{A}=\rho_{4} \alpha_{24} C_{4}^{l r}(1-F)+\rho_{3} \alpha_{23} C_{3}^{l r} F,
$$

we can combine Eqn. 4 and 5 to yield a general expression for the Os/Ir ratio of pelagic sediments, 


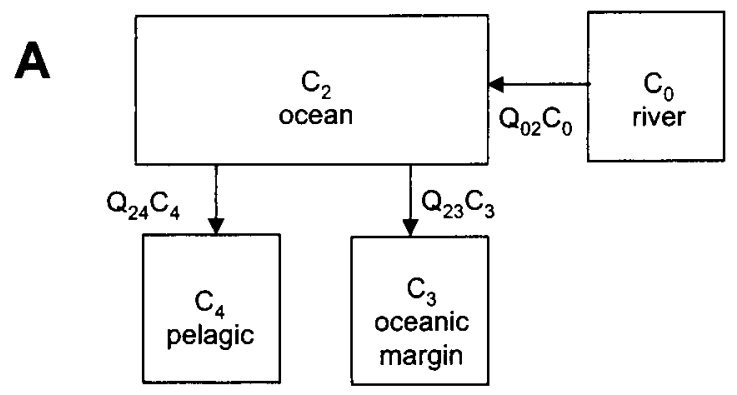

B
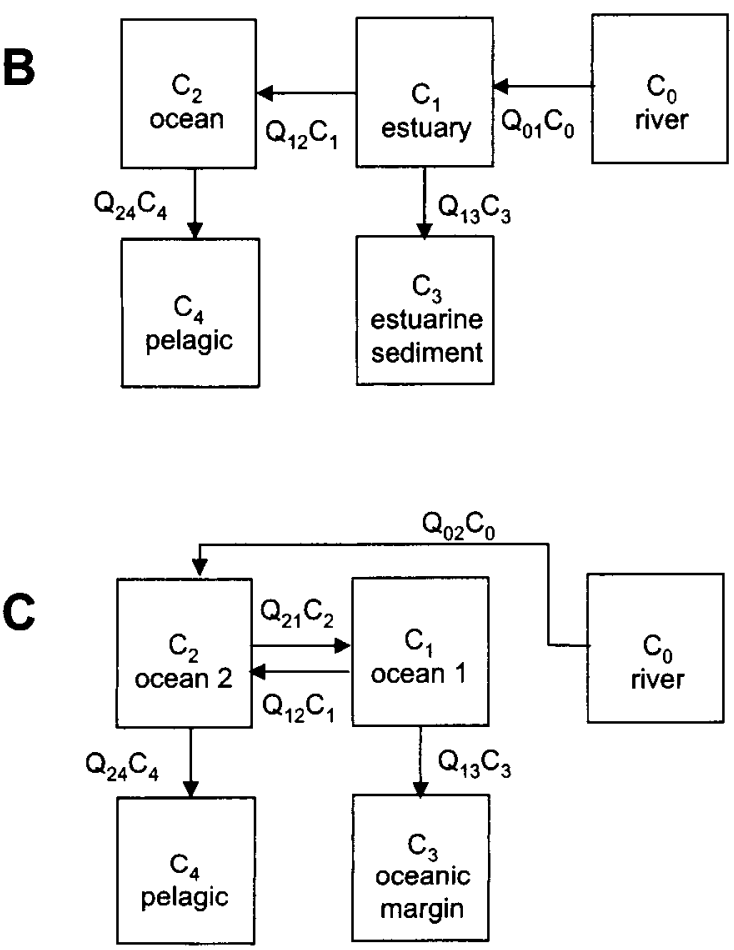

Fig. 7. Box models describing two different scenarios in which there is a missing sink. (A) Scenario A. Both sinks are located in the oceans, where $Q_{02}, Q_{24}$, and $Q_{23}$ are the mass flow of river water (reservoir 1) into the ocean (reservoir 2), pelagic sediment accumulation (reservoir 4), and sediment accumulation in hemipelagic environments (reservoir 3). $C_{0}, C_{2}, C_{3}$, and $C_{4}$ represent the concentrations of an element in river water, seawater, hemipelagic sediment, and pelagic sediment, respectively. (B) Scenario B. One of the sinks occurs between the river and the ocean, i.e. in estuaries (reservoir 1), thereby reducing the actual amount of an element entering the open ocean (reservoir 2). Variables as in scenario $A$, except $Q_{01}, Q_{12}$, and $Q_{13}$ represent the river flow into the estuarine water reservoir, mass accumulation rate of estuarine sediments, and water flow from the estuarine reservoir to the ocean. (c) Scenario A modified by placing a wall in the ocean, generating two boxes, 1 and 2. $Q_{12}$ and $Q_{21}$ represent the mass flow of water between boxes 1 and 2 .

does not include the fraction of extraterrestrial influx to continents, which is assumed to eventually enter the ocean via rivers. The mass balance of $\mathrm{Os}$ in the oceanic reservoir (reservoir 2) is then given by $0=(1+\beta) Q_{02} C_{0}-Q_{23} C_{3}-Q_{24} C_{4}$. Dividing this equation by $\mathrm{Q}_{02} \mathrm{C}_{0}$ and letting $\mathrm{f}_{23} \equiv \mathrm{Q}_{23} \mathrm{C}_{3} / \mathrm{Q}_{02} \mathrm{C}_{0}$ and $\mathrm{f}_{24} \equiv \mathrm{Q}_{24} \mathrm{C}_{4} / \mathrm{Q}_{02} \mathrm{C}_{0}$, the following form of the equation can be obtained, where the input and output terms are expressed in fractional form relative to the riverine input term

$$
\mathrm{f}_{23}+\mathrm{f}_{24}=1+\beta
$$

Eqn. 2 simply states that the fractional amount of riverine Os buried in oceanic margins $\left(f_{23}\right)$ and in the deep sea $\left(f_{24}\right)$ is equal to one plus the fractional amount of nonriverine input relative to the riverine input $\beta$.

In scenario B (Fig. 7B), Os is removed when rivers (reservoir $0)$ pass through estuaries en route to the ocean (reservoir 1), thus diminishing the actual amount of Os released to the open ocean (reservoir 2). Reservoir 3 represents the estuarine sediment and reservoir 4 represents the pelagic sediment. No other deep-sea sink is included in this scenario. As in scenario A, we define the fraction of all nonriverine inputs directly into oceans relative to the riverine input as $\beta \equiv$ (total mass flow of nonriverine inputs directly to the oceans $) /\left(\mathrm{Q}_{01} \mathrm{C}_{0}\right)$. The Os mass balance for the oceanic reservoir (2) is then given by $0=$ $\beta Q_{01} C_{0}+Q_{12} C_{1}-Q_{24} C_{4}$ and that for the estuarine reservoir (l) is given by $0=Q_{01} C_{0}-Q_{13} C_{3}-Q_{12} C_{1}$, where $Q_{13}$ and $\mathrm{Q}_{24}$ are the estuarine and pelagic sediment mass accumulation rates. We assume that nonriverine input into estuaries with concurrent removal is negligible. The mass balance equation for reservoir 1 can be rearranged to give $\left(1-f_{13}\right)=\left(Q_{12} C_{1} /\right.$ $Q_{01} C_{0}$ ) where $f_{13}$ is the mass fraction of riverine Os lost from the river and sequestered in estuarine sediments (reservoir 3 ), e.g., $f_{13} \equiv\left(Q_{13} C_{3}\right) /\left(Q_{01} C_{0}\right)$. The mass balance equation for the oceanic reservoir can then be expressed as $0=Q_{01} C_{0}\left(1-f_{13}\right)$ $+\beta \mathrm{Q}_{01} \mathrm{C}_{0}-\mathrm{Q}_{24} \mathrm{C}_{4}$. Dividing by the unmodified riverine input $\mathrm{Q}_{01} \mathrm{C}_{0}$ and expressing the fractional burial of riverine $\mathrm{Os}$ in pelagic sediments as $\mathrm{f}_{24}=\mathrm{Q}_{24} \mathrm{C}_{4} / \mathrm{Q}_{01} \mathrm{C}_{0}$, we obtain the fractional form of the oceanic reservoir mass balance:

$$
\mathrm{f}_{13}+\mathrm{f}_{24}=1+\beta \quad\left(0<\mathrm{f}_{13}<1\right)
$$

Although Eqn. 3 appears identical in form to Eqn. 2, there is a subtle but important difference. Because $f_{13}$ represents the fractional amount of riverine Os removed in estuaries, $f_{13}$ cannot be greater than 1 because the nonriverine inputs into the ocean, by construct of this model, never interact with estuaries (Fig. 7B). In the extreme case of $f_{13}=1$, there is no riverine input of Os into the ocean, and thus, Eqn. 3 requires $f_{24}=\beta$, that is the pelagic burial of Os equals the total nonriverine Os inputs.

A minimum estimate of the Os removal rates in oceanic margins in scenario A can be determined from mass balance (Eqn. 2) by using the pelagic burial rates and riverine input rates given in Table 4 . This calculation shows that pelagic sediments account for $<10 \%$ of the total riverine Os input, $<0.1 \%$ of the total Re input, and all of the Ir input to within error. If scenario A describes Os transport, then at least $90 \%$ of the Os and essentially all of the Re must be buried in oceanic margin environments. If anoxic marine sediments represent the other sink for Os and $\mathrm{Re}$ in the oceans, the present areal distribution $\mathbf{F}$ of anoxic sediments in the oceans $(\sim 0.3 \%)$ can be used to estimate the minimum burial flux of $\mathrm{Os}$ and $\mathrm{Re}$ in this missing sink (Table 4). The Os burial flux in anoxic sediments required to balance the pelagic sediment burial flux is found to be at least $3 \times 10^{5} \mathrm{pg} / \mathrm{m}^{2} \mathrm{yr}$, whereas that for $\mathrm{Re}$ is 


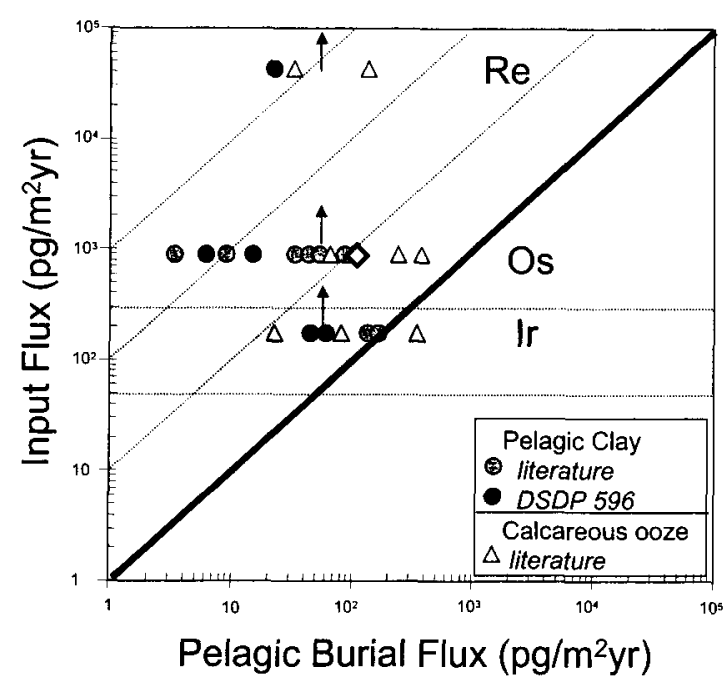

Fig. 6. Comparison of Re, Os, and Ir input (Table 2) and pelagic output fluxes for different lithologies (Table 3). The minimum input flux is represented by the riverine input (arrows denote lower bound). Each data point assumes that the entire ocean floor is covered by a particular lithology. The average burial of Os in deep-sea sediments, assuming a $1: 1$ ratio of calcareous oozes and pelagic clays, is $\sim 115$ $\mathrm{pg} / \mathrm{m}^{2}$ yr and is denoted by the open diamond. The two points for DSDP 596 refer to burial flux estimates for portions of the stratigraphic section having different sedimentation rates. Bold diagonal line represents one-to-one correspondence, in which the pelagic burial flux balances the riverine input (dashed lines represent deviations from the one-to-one line at 10 -fold increments).

Ehrenbrink and Ravizza, 2000). Exactly where the "missing" Re and Os lies is of immediate concern because it bears directly on understanding how $\mathrm{Re}$ and Os are transported in the hydrosphere. In particular, the calculated residence times of $\operatorname{Re}$ and/or Os in seawater depend critically on the number of $\mathrm{Re}$ and Os sinks and their respective removal rates. If estuarine removal is the dominant removal process of riverine Re and Os, the calculated residence times will be significantly different than in the case in which the removal occurs predominantly in a single uniform deep ocean sink. One means of identifying the extra sinks can be had by studying estuaries and oceanic margin environments themselves. However, in the case of Os, the relative importance of such sinks is not known very well. Martin et al. $(2000,2001)$ and Levasseur et al. (2000) show that dissolved Os is removed from waters in estuarine environments. In detail, however, there are subtle, but important, differences between these studies. Martin et al. (2001) suggest that a significant component of oceanic Os may be sequestered in tropical estuaries, whereas Levasseur et al. (2000) argue that a large amount of dissolved riverine $O$ s is sequestered in estuarine sediments. Thus, even though studying oceanic margins and estuaries clearly yields valuable information, the highly variable depositional and chemical conditions in oceanic margins and estuaries makes it difficult to representatively sample Os deposition in these environments. In contrast, the spatial variation of Re-PGE concentrations in the open oceans is more constant. In this section, pelagic sediments and simple mass balance principles are therefore explored to construct a more generalized model for $\mathrm{Re}$, Os, and Ir transport in the hydrosphere.

We examine two end-member steady-state scenarios describing the transport of Re-PGEs. The formulations are focused on Os, but can be applied to other elements. In scenario A, the extra Os sink is taken to occur in oceanic margins (e.g., hemipelagic environments, suboxic and anoxic marine basins, etc.). In scenario B, the extra Os sink is taken to occur in estuarine environments. Both of these scenarios are represented as box models, as shown in Figure 6.

In scenario A (Fig. 7A), Os from rivers (reservoir 0 ) flows into the ocean (reservoir 2) and is sequestered in pelagic sediments (reservoir 4) and oceanic margin sediments (reservoir 3). We also include the net contribution of other inputs of Os into the ocean (cosmic infall, hydrothermal influx, Aeolian infall, and groundwater flow), which are poorly quantified. The ocean is assumed to be well-mixed. The mass flow $(\mathrm{kg} / \mathrm{yr})$ of river water into oceans is denoted by $\mathrm{Q}_{02}$, and the mass accumulation rates of pelagic and oceanic margin sediments in the oceans are given, ,respectively by $Q_{24}$ and $Q_{23}$, where $Q_{i j}$ for sediments is equal to $\alpha_{i j} \rho_{j} \mathrm{~A}_{j}$ ( $\alpha_{i j}$ is the sedimentation rate from $i$ to $j, \rho_{j}$ is the dry weight density of the sediment, and $A_{j}$ is the area covered by the $j$ th reservoir). Let $C_{0}, C_{3}$, and $C_{4}$ be the concentrations of the element of interest in river water, oceanic margin sediments, and pelagic sediments, respectively. We define the fraction of all nonriverine inputs into the ocean relative to the riverine input as $\beta \equiv$ (total mass flow of nonriverine inputs directly into the ocean $) /\left(\mathrm{Q}_{02} \mathrm{C}_{0}\right)$. Defined in this manner, nonriverine inputs represent only direct inputs into the ocean. For example, in the case of extraterrestrial influx, $\beta$

Table 4. Calculated burial fluxes in oceanic margins based on average petagic and riverine fluxes.

\begin{tabular}{cccccc}
\hline Element & Lithology & $\begin{array}{c}\text { Average burial } \\
\text { flux in pelagic } \\
\text { sediments } \\
\left(\mathrm{pg} / \mathrm{m}^{2} \mathrm{yr}\right)\end{array}$ & $\begin{array}{c}\text { Riverine flux } \\
\left(\mathrm{pg} / \mathrm{m}^{2} \mathrm{yr}\right)\end{array}$ & $\begin{array}{c}\text { Fraction of total } \\
\text { burial required in } \\
\text { ocean margin } \\
\text { sinks }\end{array}$ & $\begin{array}{c}\text { Burial flux in anoxic } \\
\text { sediments } \\
(\mathrm{F}=0.3 \%) \\
\left(\mathrm{pg} / \mathrm{m}^{2} \mathrm{yr}\right)\end{array}$ \\
\hline Ir & Pelagic clay & 103 & 175 & 0.41 & $2.4 \times 10^{4}$ \\
Ir & Calcaraeous ooze & 147 & 175 & 0.16 & $9.3 \times 10^{3}$ \\
Ir & $1: 1$ pelagic-calcareous & 125 & 175 & 0.29 & $1.7 \times 10^{4}$ \\
Os & Pelagic clay & 33 & 898 & 0.96 & $2.9 \times 10^{5}$ \\
Os & Calcaraeous ooze & 198 & 898 & 0.78 & $2.3 \times 10^{5}$ \\
Os & $1: 1$ pelagic-calcareous & 115 & 898 & 0.87 & $2.6 \times 10^{5}$ \\
$\operatorname{Re}$ & Pelagic clay & 23 & 42681 & 0.9995 & $1.4 \times 10^{7}$ \\
$\operatorname{Re}$ & Calcaraeous ooze & 87 & 42681 & 0.9980 & $1.4 \times 10^{7}$ \\
$\operatorname{Re}$ & $1: 1$ pelagic-calcareous & 55 & 42681 & 0.9987 & $1.4 \times 10^{7}$ \\
\hline
\end{tabular}


Table 3. Pelagic burial fluxes."

\begin{tabular}{|c|c|c|c|c|c|c|c|}
\hline Element and site & Reference & Lithology & Location & $\begin{array}{c}\mathrm{C}_{4} \\
\text { conc. in } \\
\text { Dry sed } \\
\text { (pg/g) }\end{array}$ & $\begin{array}{c}\alpha_{24} \\
\text { sed. rate } \\
\text { (m/Ma) }\end{array}$ & $\begin{array}{c}\alpha_{24} \rho \mathrm{C}_{4} \\
\text { pelagic } \\
\text { burial flux } \\
\mathrm{pg} / \mathrm{m}^{2} \mathrm{yr}\end{array}$ & $\begin{array}{c}\tau_{2 \mathrm{~B}} \\
\text { apparent } \\
\text { residence } \\
\text { time }(\mathrm{yr})\end{array}$ \\
\hline \multicolumn{8}{|l|}{$\Pi$} \\
\hline DSDP $596(>5 \mathrm{Ma})$ & This study & Pelagic clay & $S$ Pacific & 400 & 0.4 & 61 & $6 \times 10^{3}$ \\
\hline DSDP $596(<5 \mathrm{Ma})$ & This study & Pelagic clay & S Pacific & 300 & 0.4 & 46 & $9 \times 10^{3}$ \\
\hline GPC $3(15-60 \mathrm{Ma})$ & (Kyte et al., 1993) & Pelagic clay & N Central Pacific & 1800 & 0.2 & 137 & $3 \times 10^{3}$ \\
\hline GPC $3(<1.5 \mathrm{Ma})$ & (Kyte et al., 1993) & Pelagic clay & N Central Pacific & 200 & 2.2 & 167 & $2 \times 10^{3}$ \\
\hline DSDP 577 (near KTB) & (Michel et al., 1985) & Calcareous ooze & NW Pacific & 20 & 3 & 23 & $2 \times 10^{4}$ \\
\hline DSDP $292(30-40 \mathrm{Ma})$ & (Keller et al., 1987) & Calcareous ooze & W Equatorial Pacific & 20 & 45 & 342 & $1 \times 10^{3}$ \\
\hline DSDP $462(30-40 \mathrm{Ma})$ & (Keiler et al., 1987) & Clay & Equatorial Pacific & 40 & 135 & 2052 & $2 \times 10^{2}$ \\
\hline DSDP $612(30-40 \mathrm{Ma})$ & (Kefler et al., 1987) & Calcareous ooze & W Atlantic & 10 & 20 & 76 & $5 \times 10^{3}$ \\
\hline \multicolumn{8}{|l|}{ Os } \\
\hline DSDP $596(>5 \mathrm{Ma})$ & This study & Pelagic clay & S Pacific & 40 & 0.4 & 6 & $6 \times 10^{6}$ \\
\hline DSDP $596(<5 \mathrm{Ma})$ & This study & Pelagic clay & S Pacific & 100 & 0.4 & 15 & $3 \times 10^{6}$ \\
\hline GPC3 (15-60 Ma) & (Pegram et al., 1992) & Pelagic clay & N Central Pacific & 120 & 0.2 & 9 & $6 \times 10^{6}$ \\
\hline GPC3 $(<1.5 \mathrm{Ma})$ & (Pegram et al., 1992) & Pelagic clay & N Central Pacific & 70 & 2.2 & 59 & $3 \times 10^{6}$ \\
\hline $\begin{array}{l}16-162-17-4,139-140(48.7 \\
\text { Мa) }\end{array}$ & (Peucker-Ehrenbrink et al.. 1995) & Chalk & Equatorial Pacific & 38 & 3 & 43 & $9 \times 10^{5}$ \\
\hline $20-196-2-5,112-114(80 \mathrm{Ma})$ & (Peucker-Ehrenbrink et al., 1995) & Pelagic clay & NW Pacific & 182 & 1.25 & 86 & $4 \times 10^{5}$ \\
\hline $39-2-6,130-131(53 \mathrm{Ma})$ & (Peucker-Ehrenbrink et al.. 1995) & Pelagic clay & NE Pacific & 416 & 0.34 & 54 & $7 \times 10^{5}$ \\
\hline $\begin{array}{l}129-801 \mathrm{~A}-4 \mathrm{R}-2-45-47(57.1 \\
\mathrm{Ma})\end{array}$ & (Peucker-Ehrenbrink et al.. 1995) & Pelagic clay & NW Pacific & 9 & 1 & 3 & $1 \times 10^{7}$ \\
\hline 9-77B-53-1, 70-72 (37.9 Ma) & (Peucker-Ehrenbrink et al., 1995) & Pelagic clay & E Equator & 64 & 10 & 243 & $2 \times 10^{5}$ \\
\hline $34-319-12-3,134-136(15.8)$ & (Peucker-Ehrenbrink et al., 1995) & Calcareous ooze & E Equatorial Pacific & 61 & 16.5 & 382 & $1 \times 10^{5}$ \\
\hline $92-597-6-2,106-107(26.3 \mathrm{Ma})$ & (Peucker-Ehrenbrink et al., 1995) & Calcareous ooze & E Equatorial Pacific & 34 & 7.7 & 99 & $4 \times 10^{5}$ \\
\hline $8-74-12-3,18-20$ (42 Ma) & (Peucker-Ehrenbrink et al., 1995) & Calcareous ooze & Central Pacific & 75 & 2.3 & 66 & $6 \times 10^{5}$ \\
\hline \multicolumn{8}{|l|}{$\operatorname{Re}$} \\
\hline DSDP $596(>5 \mathrm{Ma})$ & This study & Pelagic clay & S Pacific & 150 & 0.4 & 23 & $1 \times 10^{9}$ \\
\hline DSDP $596(<5 \mathrm{Ma})$ & This study & Pelagic clay & S Pacific & 150 & 0.4 & 23 & $1 \times 10^{9}$ \\
\hline $8-74-12-3,18-20(42 \mathrm{Ma})$ & (Peucker-Ehrenbrink et al., 1995) & Calcareous ooze & Central Pacific & 38 & 2.3 & 33 & $9 \times 10^{8}$ \\
\hline $92-597-6-2,106-107$ (26.3 Ma) & (Peucker-Ehrenbrink et al., 1995 & Calcareous ooze & E Equatorial Pacific & 48 & 7.7 & 140 & $2 \times 10^{8}$ \\
\hline
\end{tabular}

${ }^{a}$ Notation follows that given for scenario B transport model (reservoir $0=$ river; reservoir $2=$ ocean; reservoir $4=$ pelagic sediment); $\mathrm{C}_{4}=\mathrm{dry}$ weight concentration in sediment ( $\mathrm{pg} / \mathrm{g}) ; \alpha_{24}=$ sedimentation rate $(\mathrm{m} / \mathrm{Ma})$; pelagic burial flux is $\mathrm{Q}_{24} \mathrm{C}_{4}$ or $\alpha_{24} \rho \mathrm{C}_{4}$, where $\rho$ is the dry weight density (assumed to be $\left.-0.38 \mathrm{~g} / \mathrm{cm}^{3}\right) ; \tau_{2 B}=$ residence time for transport model of scenario $\mathrm{B}=\left(\mathrm{C}_{2} \mathrm{M}_{2}\right) /\left(\alpha_{24} \rho \mathrm{C}_{4} \mathrm{~A}_{2}\right)$, where $\mathrm{A}_{2}$ is the area of the ocean $(3.61$ $\left.\times 10^{14} \mathrm{~m}^{2}\right), M_{2}$ is the mass of the ocean $\left(1.4 \times 10^{21} \mathrm{~kg}\right)$, and $C_{2}$ is the concentration in the ocean (Table 2); sediment accumulation rates and ages are based on biostratigraphic data and can be found from the Initial Reports of the Deep Sea Drilling Project (volumes 8, 9, 16, 20, 34, 39, 86, 91, 92, and 129) or from Kyte et al. (1993) and Zhou and Kyte (1992) for GPC 3 and DSDP 596, respectively.

oozes and if we generalize the limited data set, then it can be seen that burial fluxes of Os and Re in calcareous oozes are higher, whereas that for Ir does not change to within error. The higher burial fluxes for $\mathrm{Os}$ and $\mathrm{Re}$ in calcareous oozes is due mainly to the high sedimentation rates ( 1 to 2 orders of magnitude higher than pelagic clay accumulation rates, Table 3). Presently, calcareous oozes make up $<50 \%$ of the Pacific Ocean, $\sim 60 \%$ of the Atlantic Ocean, and $\sim 50 \%$ of the Indian Ocean (Davies and Gorsline, 1976). Assuming a 1:1 ratio of calcareous oozes to pelagic clays, the average deep-sea burial flux of Os would be $115 \mathrm{pg} / \mathrm{m}^{2} \mathrm{yr}$, which is shown as a diamond in Figure 6 and tabulated in Table 4 (average pelagic clay burial flux for Os is 34 and that for calcareous oozes is 198). This value accounts for only $\sim 13 \%$ of the riverine input of Os (900 $\mathrm{pg} / \mathrm{m}^{2} \mathrm{yr}$ ). Given that our estimate of the Os input is a minimum bound for the total Os input into the oceans, Os burial in deep-sea sediments in the present-day oceans clearly does not balance the Os input. Moreover, the present day areal distribution of pelagic calcareous sediments may be the highest it has ever been since the Cretaceous (Opdyke and Wilkinson, 1988). Opdyke and Wilkinson (1988) showed that the total rate of pelagic limestone accumulation is approximately eight times higher at the present as compared with the end of the Creta- ceous. Calcareous oozes therefore cannot solve the problem of missing Os in the deep-sea.

In summary, we conclude that deep-sea sediments represent a much larger sink for Ir than for Os and Re. Mass balance considerations assuming the riverine Re-PGE inputs represent a minimum estimate of the total inputs into the ocean indicate that at least $95 \%$ and $99.9 \%$ of the total oceanic input of Os and Re, respectively, must be sequestered in sinks other than deepsea sediments. These extra sinks could be located in oceanic margins or estuaries. The amount of Ir sequestered in these extra sinks must be much smaller than Os and Re, but the exact amount is not known because the total oceanic input of Ir is unconstrained. In the next section, we use simple models to speculate where the "missing" Os and Re resides.

\subsection{Implications for the Transport of Re, Ir, and Os}

The last section demonstrated that other sinks for Re and Os must exist besides pelagic sediments. Numerous studies have shown that $\mathrm{Re}$ and $\mathrm{O}$ s can be sequestered in oceanic margins (e.g., anoxic and suboxic sediments in hemipelagic environments or marginal basins) and in estuaries (Colodner et al., 1993; Levasseur et al., 2000; Martin, 2000, 2001; Peucker- 
Table 2. Riverine fluxes. ${ }^{a}$

\begin{tabular}{ccccc}
\hline Element & $\begin{array}{c}\mathrm{C}_{0} \\
\text { Conc. in } \\
\text { river }(\mathrm{pg} / \mathrm{kg})\end{array}$ & $\begin{array}{c}\mathrm{Q}_{02} \mathrm{C}_{0} / \mathrm{A}_{2} \\
\text { Riverine flux } \\
\left(\mathrm{pg} / \mathrm{m}^{2} \mathrm{yr}\right)\end{array}$ & $\begin{array}{c}\mathrm{C}_{2} \\
\text { Conc. in } \\
\text { ocean }(\mathrm{pg} / \mathrm{kg})\end{array}$ & $\begin{array}{c}\tau_{2 \mathrm{~A}} \\
\text { residence } \\
\text { time }(\mathrm{yr})\end{array}$ \\
\hline $\mathrm{Ir}$ & 1.75 & 175 & 0.1 & $2 \times 10^{3}$ \\
$\mathrm{Os}$ & 9 & 898 & 10 & $4 \times 10^{4}$ \\
$\mathrm{Re}$ & 428 & 42681 & 8000 & $7 \times 10^{3}$ \\
\hline
\end{tabular}

atation follows that used for scenario A box model (reservoir $0=$ river; reservoir $2=$ ocean); $C_{0}=$ concentration in river water; $Q_{02}=$ global river flow $\left(3.6 \times 10^{16} \mathrm{~kg} / \mathrm{yr}\right) ; \mathrm{A}_{2}=$ area of ocean $\left(3.61 \times 10^{14}\right.$ $\left.\mathrm{m}^{2}\right) ; \tau_{2 A}=$ residence time for scenario $A=\left(C_{2} M_{2}\right) /\left(Q_{02} C_{0}\right)$, where $M_{2}$ is the mass of the ocean $\left(1.4 \times 10^{21} \mathrm{~kg}\right)$; oceanic and river concentrations of Os, Ir, and Re are from Anbar et al. (1992), Colodner et al. (1993), Anbar et al. (1996), Sharma and Wasserburg (1997), Levasseur et al. (1999), and Peucker-Ehrenbrink and Ravizza (2000).

fractionation of the K-T impactor's Os and Ir was probably widespread in the marine environment. The majority of Os from the K-T impactor therefore had to be soluble, allowing it to be separated from Ir (which could be either in a soluble or insoluble form) and deposited elsewhere besides the deep sea. This conclusion is consistent with that made by Peucker-Ehrenbrink (1996), which is based on fewer data for DSDP 596.

It is likely that this fractionation of Os from Ir during the K-T interval is also a general process throughout geologic time. The Os/Ir ratio throughout the rest of the DSDP 596 section is far less than the chondritic ratio of 1 , ranging from 0.06 at the KTB to 0.4 just below the sediment-water interface (Fig. 3). Subchondritic Os/Ir ratios have also been observed in other pelagic sediments (Koide et al., 1991; Ravizza and Pyle, 1997; Ravizza et al., 2001). These subchondritic ratios in pelagic sediments contrast with the chondritic to slightly superchondritic Os/Ir ratios in the main inputs of Os and Ir into the oceans (extraterrestrial influx $\sim 1$ (Brownlee et al., 1984; Peucker-Ehrenbrink, 1996), continental crust $\sim 1$ (Peucker-Ehrenbrink and Jahn, 2001), rivers $\sim 3$ to 16 (Anbar et al., 1996; Levasseur et al., 1999; Peucker-Ehrenbrink and Ravizza, 2000), there is at present no direct estimate of the Os/Ir ratio of the hydrothermal input, but the Os/Ir ratio of the mantle is $\sim 1$ ). Aqueous fractionation of Os from $\mathrm{Ir}$ is therefore spatially and temporally widespread (Ravizza et al., 2001). Furthermore, it can be qualitatively concluded that deep-sea sediments cannot account for all of the Os input into the oceans. In the next section, the sinks and sources of $\mathrm{Os}, \mathrm{Ir}$, and Re will be quantified by means of simple transport models.

\subsection{Oceanic Mass Balance of Os, Ir, and Re}

In this section, we seek to further assess the generality of Os/Ir fractionation in the marine environment by quantifying the magnitudes of the deep-sea Os and Ir sinks, and comparing these values to the global input of $\mathrm{Os,} \mathrm{Ir,} \mathrm{and} \mathrm{Re} \mathrm{into} \mathrm{the}$ oceans. The global input of Os, Ir, and Re into the oceans can come from rivers, extraterrestrial infall (in vapor or particle form), hydrothermal fluxing, groundwater flow or Aeolian infall. Only the riverine input is reasonably well-known, and therefore, we use the riverine input as a minimum estimate of the Os, Ir, and Re inputs into the ocean. The global riverine flux of $\mathrm{Os}, \mathrm{Ir}$, and $\mathrm{Re}$ are tabulated in Table 2, where the riverine flux is equal to $\mathrm{Q}_{\text {riv }} \mathrm{C}_{\mathrm{riv}} / \mathrm{A}_{\mathrm{oc}}\left(\mathrm{Q}_{\text {riv }}\right.$ is the global riverine mass flow $[\mathrm{kg} / \mathrm{yr}], \mathrm{C}_{\text {riv }}$ is the concentration $[\mathrm{pg} / \mathrm{kg}$ ] of an element in river water, and $A_{o c}$ is the area of the oceans $\left.\left[\mathrm{m}^{2}\right]\right)$. These riverine fluxes are derived from riverine concentrations prior to any estuarine removal. In Table 3 , we list the bulk pelagic sediment burial fluxes calculated from estimated sedimentation rates and bulk concentrations for various localities and pelagic lithologies in the Pacific Ocean by using the available data. The average age of the pelagic sediments used for these calculations is $\sim 40 \mathrm{Ma}$. The burial flux was expressed as $\mathrm{C}_{\text {sed }}^{\mathbf{i}} \rho \alpha$, where $\mathrm{C}_{\text {sed }}^{\mathrm{i}}$ is the dry weight concentration $(\mathrm{pg} / \mathrm{g})$ of element $i$ in the sediment, $\rho$ is the sediment dry weight density $\left(\mathrm{g} / \mathrm{cm}^{3}\right)$, and $\alpha$ is the sedimentation rate $(\mathrm{mm} / \mathrm{yr})$. Sedimentation rates were taken from the Initial Reports of the Deep Sea Drilling Project (volumes 8, 9, 16, 20,34, 39, 61, 86, 91, 95, 92, and 129) or from Kyte et al. (1993) and Zhou and Kyte (1992). The sedimentation rates are based on biostratigraphic markers. In Figure 6 , pelagic burial outputs vs. riverine inputs are compared on a logarithmic scale. Because the global riverine inputs of Os and Re are based on several studies encompassing most of the world's largest rivers (Colodner et al., 1993; Sharma and Wasserburg, 1997; Levasseur et al., 1999; Peucker-Ehrenbrink and Ravizza, 2000), the uncertainties on the estimates of the global Os and Re riverine inputs are considered to be insignificant in a logarithmic plot. The global riverine input of Ir, however, is less constrained because the data set is limited to two rivers entering the Baltic Sea and the variation in the Ir content of these two rivers is significant (Anbar et al., 1996). The range in riverine Ir input is denoted in Figure 6. For the output fluxes, each of the values given in Table 3 are plotted for various pelagic lithologies and localities for Os, Ir, and Re. In constructing Figure 6, each point reflects the deep-sea burial flux assuming the entire ocean is covered by a particular lithology. The bold diagonal line represents the condition in which the deep-sea burial fluxes equal the riverine input. Points that plot to the left of this line indicate that the pelagic burial flux for a particular lithology is less than the riverine flux. Adding other inputs into the ocean will shift the data upward (as shown by the arrows in Fig. 6), increasing the discrepancy between total oceanic inputs and burial in pelagic sediments.

It can be seen from Figure 6 that the burial flux of Os and Re associated with pelagic clays is 1 to 2 and 2 to 3 orders of magnitude lower than the riverine influx of Os and Re, respectively, whereas the pelagic clay burial flux of Ir is equal to the riverine influx of Ir to within uncertainties. A mass balance calculation based on the average of the pelagic clay burial fluxes and the riverine fluxes for Os and Re (Table 4) shows that pelagic clays account for no more than $4 \%$ and $0.05 \%$, respectively, of the total inputs of $\mathrm{Os}$ and $\mathrm{Re}$ into the ocean. For Ir (Fig. 6), the pelagic burial fluxes are equal to the riverine flux to within the uncertainty of the riverine Ir input (Anbar et al., 1996). If most of the deep-ocean is underlain by pelagic clays, then the data shown in Figure 6 indicate that pelagic clays serve as a much larger sink for Ir than for Re and Os. This generality is in accordance with the observations made in the previous section that there is a clear deficit in Os relative to Ir in pelagic clays at and away from the KTB in two pelagic sections.

We now consider calcareous oozes as a deep-sea sink for Os, $\mathrm{Re}$, and Ir. Calcareous ooze data points are shown as triangles in Figure 6. If the entire ocean were covered with calcareous 

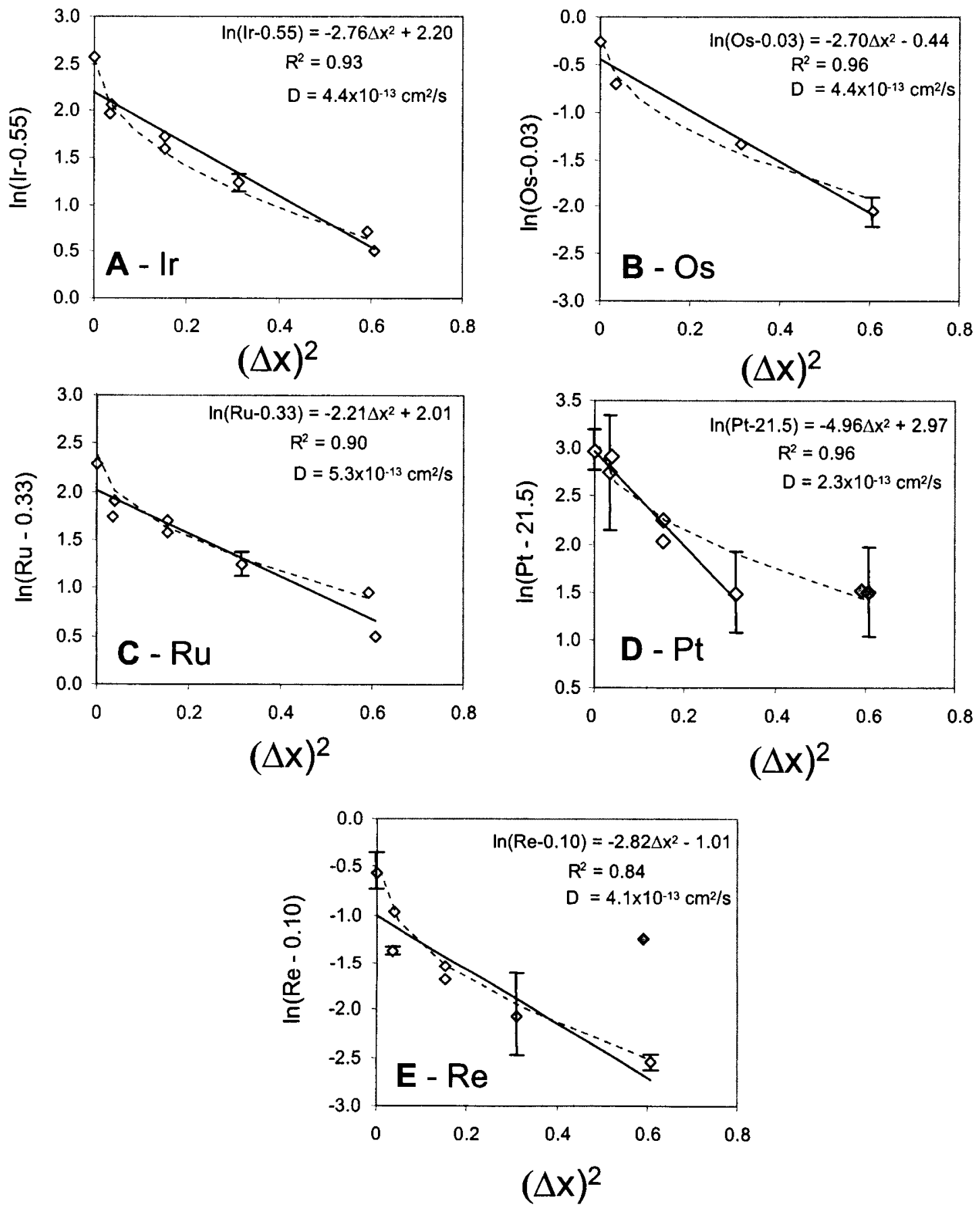

Fig. 5. Natural logarithm of the baseline-corrected concentration $\ln \left(C-C_{B}\right)$ vs. $\Delta x^{2}$, where $\Delta x$ is the absolute distance (m) from the peak. The background concentration is estimated from the data points away from the KTB Re-PGE anomaly. Error bars incorporate the two standard deviation of duplicate runs and an arbitrary $10 \%$ error on our choice of the background correction. The diffusional redistribution model of an instantaneous flux of Re-PGEs predicts a linear relationship in $\ln \left(C-C_{B}\right)-\Delta x^{2}$, with a slope equivalent to $-1 /(4 D t)$, where $D$ is the effective diffusivity $\left(\mathrm{cm}^{2} / \mathrm{s}\right)$. Effective diffusivities for Re, $\mathrm{Pt}, \mathrm{Ir}$, Os, and $\mathrm{Ru}$ are shown for a diffusional timescale of $65 \mathrm{Ma}$. For $\mathrm{Re}$ and $\mathrm{Pt}$, linear regression lines were made by ignoring one and two outliers (gray diamonds), respectively. Also shown are the empirical fits of the data to an exponential decay function, $C=C_{0} \mathrm{e}^{-\mid \Delta x / /}$ and plotted in $\ln \left(C-C_{B}\right)-\Delta x^{2}$ space (curved dashed line). Fits to the exponential function include all data points. Exponential fits are as follows: $\mathrm{Ir}=12.98 \mathrm{e}^{-2.48 \Delta x}\left(r^{2}=0.98\right)$, Os $=0.779 \mathrm{e}^{-2.20 \Delta x}\left(r^{2}=0.99\right), \mathrm{Ru}=9.86 \mathrm{e}^{-1.96 \Delta x}\left(r^{2}=0.92\right), \mathrm{Re}=0.536 \mathrm{e}^{-2.49 \Delta x}\left(r^{2}=0.96\right)$, and $\mathrm{Pt}=21.4 \mathrm{e}^{-2.17 \Delta x}\left(r^{2}\right.$ $=0.89$ ). 
ground), $C_{T}$ is the total amount of the PGE per unit area ( $\mathrm{ng} / \mathrm{m}^{2}$ ), $\rho$ is the dry weight density, $D$ is the effective diffusivity $\left(\mathrm{m}^{2} / \mathrm{s}\right), t$ is time (s), and $\Delta x$ is distance (m) away from the peak (Crank, 1975). Such a diffusion profile yields a linear relationship when $\ln C$ is plotted against $\Delta x^{2}$, with the slope of the line being inversely proportional to the diffusivity (slope $=$ $-1 / 4 D t$ ). Figure 5 shows that the concentration profiles yield strong linear correlations in $\operatorname{lnC}-\Delta x^{2}$ space for $\mathrm{Ir}, \mathrm{Ru}, \mathrm{Os}$, and $\mathrm{Re}$, and weak correlations for Pt. We did not attempt to plot Pd in $\ln C-\Delta x^{2}$ space because of the large uncertainty in calculating the background-corrected Pd concentration. The strong linear correlations for $\mathrm{Ir}, \mathrm{Ru}, \mathrm{Os}, \mathrm{Re}$, and to a lesser extent $\mathrm{Pt}$ are suggestive of diffusional redistribution. Assuming diffusion has operated since the time of deposition $(\sim 65 \mathrm{Ma})$, the effective diffusivities are calculated to be between 2.3 to $5.3 \times$ $10^{-13} \mathrm{~cm}^{2} / \mathrm{s}$ for Re, Pt, Ir, Ru, and Os. These effective diffusivities are significantly lower than those of soluble cations in pore waters $\left(10^{-6} \mathrm{~cm}^{2} / \mathrm{s}\right.$; McDuff, 1981), implying Re-PGE diffusion is limited by chemical reaction (limited solubility, adsorption, etc.) between the solid phases and interstitial pore waters. In making these calculations, we eliminated one Re and two Pt data outliers (Fig. 5). However, including these points does not change the above range of calculated diffusivities, i.e., the diffusivities remain identical to within a factor of about two. If the redistribution of Re-PGE at the KTB was indeed controlled by diffusion, the similarity in effective diffusivities indicates that Re-PGE abundances cannot be significantly fractionated at the peak because elemental fractionation at the peak is inversely proportional to the square root of the ratio of the elemental diffusivities.

Although the diffusion model appears to describe the data, Zhou et al. (1991) report the presence of shocked quartz in one spot $\sim 0.5 \mathrm{~m}$ below the Ir peak, which clearly requires mechanical redistribution, such as bioturbation. However, bioturbation of an initial PGE spike predicts an exponentially decreasing PGE profile (Berger and Heath, 1968), which is inconsistent with the symmetric Re-PGE profile. Bioturbation should lead to exponentially decreasing Ir concentrations with increasing distance up-section, e.g., $C=C_{0} \mathrm{e}^{-z / L}$, where $z$ is the distance (or the sedimentation rate $\times$ time) from the base of the initial homogenization zone of width $L$ (located a distance $L$ below the initial deposition layer), and $C_{0}$ is the concentration at $z=$ 0 . We note that both the down-section and up-section legs of the $\mathrm{Re}, \mathrm{Pt}$, Ir, Os, and $\mathrm{Ru}$ profiles can each be fit to an exponentially decaying function (dashed lines in Fig. 5), but such profiles have no physical relevance to the simple bioturbation model described above, which predicts one-sided exponential decay, and hence an asymmetric profile. In addition, the calculated bioturbation lengthscale is $\sim 0.5 \mathrm{~m}$, which is much larger than the $0.02-$ to $0.1-\mathrm{m}$ lengthscale observed in most sediments (Thomson et al., 2000). If bioturbation is responsible for postdepositional redistribution of Re-PGEs, a more complex bioturbation model is clearly needed to explain the data. Besides the one sample lying $\sim 0.5 \mathrm{~m}$ below the Re-PGE peak, Zhou et al. (1991) did not examine other points away from the immediate vicinity of the peak for shocked quartz. It is therefore not possible to determine if this particular sample containing shocked quartz indicates widespread homogenization by bioturbation or if this sample fortuitously encountered an iso- lated worm hole, which extends well below the homogenization zone (Lowemark and Werner, 2001).

Regardless of what caused the redistribution of Re-PGEs, the fact that these elements were redistributed over the same lengthscale indicates that they remained remarkably coupled during redistribution. Thus, the fractionated Re-PGE compositions were not imposed by postdepositional redistribution processes. Instead, fractionation of Re-PGE at the KTB appears to have occurred in the aqueous marine environment.

\subsection{Fractionations of $\mathrm{Os} / \mathrm{Ir}$ at Pelagic KTB Sites}

The most striking result of this study is that the two pelagic KTB sediments have highly fractionated Re-PGE patterns, contrasting with the two hemipelagic KTB sediments, which have near-chondritic PGE patterns. The largest and most consistent fractionation appears to be a depletion in Os relative to Re and the other PGEs, as exemplified by extremely subchondritic Os/Ir ratios (0.06 to 0.08) for the KTB at DSDP 596 and $465 \mathrm{~A}$. This result agrees with the combined Os measurements by Peucker-Ehrenbrink et al. (1995) and the Ir measurements by Kyte et al. (1996). Relative to the chondritic value of Os/Ir $=1$, the measured Os/Ir ratios correspond to 90 to $95 \%$ depletion in Os. Similar magnitude depletions in Os relative to Ir have been seen at the KTB in a pelagic Caribbean Sea section (ODP Site 1001; Pearson et al., 1999) and a central Pacific pelagic site (LL44-GPC3; Kyte et al., 1993; Pegram and Turekian, 1999). Collectively, this suggests that subchondritic Os/Ir appears to be a widespread feature of deep-sea KTB sediments.

One possibility for nonchondritic Os/Ir is that the K-T impactor had a nonchondritic Os/Ir ratio. This seems unlikely because the $\mathrm{Cr}$ isotopic composition of KTB sediments is similar to that of carbonaceous chondrites (Shukolyukov and Lugmair, 1998), and most meteorites (chondrites and metals) have an Os/Ir ratio of $\sim 1$ (Larimer and Wasson, 1988). In addition, this hypothesis would require an alternative explanation for the chondritic PGE abundance pattern of the two hemipelagic sites analyzed here. If we assume the K-T impactor had chondritic Re-PGE abundance patterns, then the fractionations must have occurred in the marine environment. In the case of DSDP 596, postdepositional redistribution of Os in the sedimentary column cannot explain the deficit in Os relative to $\mathrm{Ir}$ at the KTB because there is not enough Os anywhere in the core to balance the deficit. To illustrate, the Os/Ir ratio calculated by integrating over the elevated Os and Ir profiles $(\sim 1.8$ $\mathrm{m}$ ) associated with the KTB remains strongly subchondritic. In addition, even if all of the Os in the entire stratigraphic column is integrated and combined with only the total amount of Ir present in the $\sim 1.8$-m-wide interval containing the KTB (total Os in sedimentary column calculated assuming a total sediment thickness of $70.5 \mathrm{~m}$ and a constant Os concentration of 0.1 $\mathrm{ppb}$ ), the $\mathrm{Os} / \mathrm{Ir}$ ratio is raised from 0.06 to only 0.33 , which is well below the chondritic value.

The above calculations require the "missing" Os from the KTB in DSDP 596 to be deposited elsewhere besides this deep-sea sediment core and without Ir. Combined with the fact that the only four pelagic KTB sections analyzed so far for both Os and Ir are also characterized by distinctly subchondritic Os/Ir ratios (DSDP 465 and 596, LL44-GPC3, ODP-1001), 